CUADERNOS DE ESTUDIOS GALLEGOS, LXIII Núm. 129 (enero-diciembre 2016), págs. 205-242

ISSN: $0210-847 \mathrm{X}$

DOI: $10.3989 /$ ceg.2016.129.06

\title{
DE ALCABALAS Y ARRENDADORES. LA CONTRIBUCIÓN DE CONCEJOS Y PARROQUIAS ASTURIANAS A LA HACIENDA REGIA EN 1494*
}

\author{
María Álvarez Fernández \\ Universidad de Oviedo
}

*Esta investigación ha formado parte del Proyecto de Investigación financiado por el Ministerio de Economía y Competitividad Poder, sociedad y fiscalidad en el entorno geográfico de la Cornisa Cantábrica en el tránsito del Medievo a la Modernidad (HAR2011-27016-C02-01) con sede en la UPV/EHU y parte del Proyecto Coordinado HAR2011-27016-C02-00, junto con el Proyecto de Investigación HAR2011-27016-C02-02 de la Universidad de Valladolid y ha participado asimismo de la Red Arca Comunis.

Copyright: (C) 2016 CSIC. Este es un artículo de acceso abierto distribuido bajo los términos de una licencia de uso y distribución Creative Commons Attribution (CC-by) España 3.0.

Cómo citar/Citation: María Álvarez Fernández, "De alcabalas y arrendadores. La contribución de concejos y parroquias asturianas a la hacienda regia en 1494", Cuadernos de Estudios Gallegos, 63, núm. 129 (2016), págs. 205-242, DOI: http://dx.doi.org/10.3989/ceg.2016.129.06 


\section{DE ALCABALAS Y ARRENDADORES. LA CONTRIBUCIÓN DE CONCEJOS Y PARROQUIAS ASTURIANAS A LA HACIENDA REGIA EN 1494}

\section{RESUMEN}

Custodiado en el rico fondo documental de Contaduría Mayor de Cuentas del Archivo General de Simancas se halla una interesante relación de las rentas de alcabalas tributadas por el Principado de Asturias en tiempos de Isabel I de Castilla en la que se desglosa pormenorizadamente la imposición debida por cada uno de los concejos asturianos y la distribución parroquial de las cargas totales (1494). Queremos, con nuestro estudio, presentar a la comunidad científica interesada en la fiscalidad regia castellana a fines del Medievo un excepcional testimonio de la presión fiscal a la que fue sometido el Principado de Asturias en los años finales del siglo XV con la intención de que pueda ser considerado en futuros análisis comparativos sobre haciendas regias en la cornisa cantábrica para el periodo indicado.

PAlABRAS ClAVE: fiscalidad, alcabala, situado, hacienda regia, Asturias, Edad Media.

\section{DE ALCABALAS E ARRENDADORES. A CONTRIBUCIÓN DE CONCELLOS E PARROQUIAS ASTURIANAS Á FACENDA REXIA EN 1494}

\section{Resumo}

Custodiado no rico fondo documental de "Contaduría Mayor de Cuentas" do Arquivo Xeral de Simancas áchase unha interesante relación das rendas de alcabalas tributadas polo Principado de Asturias en tempos de Isabel I de Castela na que se desagrega pormenorizadamente a imposición debida por cada un dos concellos asturianos e a distribución parroquial das cargas (1494). Queremos, co noso estudo, presentar á comunidade científica interesada na fiscalidade rexia castelá a fins do Medievo un excepcional testemuño da presión fiscal á que foi sometido o Principado de Asturias nos anos finais do século XV coa intención de que poida ser considerado en futuras análises comparativas sobre as facendas rexias na cornixa cantábrica para o período indicado.

Palabras ClaVe: fiscalidade, alcabala, situado, facenda rexia, Asturias, Idade Media.

\section{OF “ALCABALAS” AND LANDLORDS. THE CONTRIBUTION OF ASTURIAN COUNCILS AND PARISHES TO THE ROYAL TREASURY IN 1494}

\section{AbSTRACT}

The rich documentary fund of the Contaduria Mayor de Cuentas -the Higher Accounting Office of Castile-contained in the Archivo General de Simancas preserves an interesting account of the incomes from the alcabalas - a sale tax applied to certain products-collected in the Principality of Asturias in times of Isabel I of Castile. This document provides a detailed list of the taxes owed by each of the Asturian municipalities and the parish tax allocation in 1494. In this work we aim to present to the scientific community interested in the Castilian royal taxation of the Late Middle Ages an outstanding example of the fiscal pressure experienced by the Principality of Asturias during the late fifteenth century. Our intention is that it can be considered in future comparative studies on the royal finances in the Cantabrian coast for the given period. KEY wORDs: finances, alcabala, sale tax, Royal taxation, Asturias, Late Middle Ages. 
Recibido/Received: 28/09/2015

Aceptado/Accepted: 27/06/2016

$Y$ el pueblo doliente llega a recelar, no le echen gabela sobre el respirar ${ }^{1}$. Con profundo lamento definía Francisco de Quevedo, mediado el siglo XVII, la asfixiante presión fiscal de la España de Felipe $\mathrm{IV}^{2}$. Poco más de un siglo atrás, en las Asturias de Oviedo, la percepción de los contribuyentes respecto a la carga fiscal impuesta por la Corona castellana bien podría compararse, salvando las distancias, con aquel lamento quevedesco. En efecto, a fines de la Edad Media, el cumplimiento de los deberes fiscales y financieros exigidos por la Corona puso de manifiesto las grandes dificultades económicas de las lejanas tierras asturianas para satisfacer los pagos y las contribuciones ordinarias llegadas desde la Corte, como el pago del servicio, el pedido, la moneda forera o, más tarde, la alcabala. A remolque de los acontecimientos y con una falta total de previsión presupuestaria, la fiscalidad ordinaria y los coyunturales gastos extraordinarios a los que el Principado tuvo que hacer frente no sólo mermaron la liquidez municipal de las ciudades y villas asturianas sino que acabaron por empobrecer a la población pechera, que denunciará permanentemente la política fiscal ejercida por el Principado y por la Corona ${ }^{3}$.

En esta exposición de urgencia por motivos editoriales y por la propia provisionalidad de los resultados que presentamos es, sin embargo, necesario repasar algunos de los rasgos generales de la fiscalidad asturiana medieval, a fin de comprender y contextualizar el interés del testimonio inédito que presentamos y valorar en su justa medida la relevancia de la información que contiene. Y para ello es preciso recordar, en primer lugar, que en total sintonía con lo que ocurre en

\footnotetext{
1 Siglas empleadas: AGS: Archivo General de Simancas; CMC: Contaduría Mayor de Rentas.

2 Francisco Quevedo y Villegas, Memorial. A.S.M. El Rey Don Felipe IV. Obras completas, ed. de A. Fernández-Guerra y Orbe (con notas de M. Menéndez-Pelayo), Sevilla, 1907, pág. 221.

3 Un estado de la cuestión sobre esta problemática en nuestro estudio María Álvarez FernándeZ, "Con pago leal y verdadero. Exigencias financieras y servicio a la Corona. Asturias, siglos XV y XVI", en Abastecer y financiar la Corte. Las relaciones económicas entre las cortes ibéricas y las sociedades urbanas a fines de la Edad Media, Casa Velázquez [en prensa].
} 
el resto de la Corona de Castilla, el modelo hacendístico y fiscal asturiano alcanzó ya con Alfonso $\mathrm{X}$ un alto grado de madurez, con un ámbito competencial cada vez mayor y unas cargas fiscales regias también cada vez mayores. Convertidas las ciudades, en virtud de la subrogación regia del poder señorial, en titulares de auténticos señoríos sobre bienes realengos y jurisdiccionales y percibiendo derechos de naturaleza jurídico-pública gracias a la transferencia a las haciendas locales de la gestión temporal o perpetua de ciertos impuestos, acabó por conformarse, a nivel local, una maquinaria concejil cada vez más compleja responsable de gestionar las cada vez mayores haciendas municipales ${ }^{4}$.

Dentro de las responsabilidades fiscales debidas por las ciudades asturianas al monarca en aquel siglo XIII se pueden rastrear, a pesar del laconismo documental asturiano, algunos conceptos de tributación directa e indirecta que, ya desde el propio fuero de población ovetense de 1145, están revelando las exigencias financieras debidas a la Corte ${ }^{5}$. En pleno siglo XIII, la política financiera de los reyes castellanos combinó la exención fiscal -reducciones parciales o totales de determinadas cargas, como la fonsadera o el yantar, pagado sólo en Asturias en caso de visita regia- con la imposición de nuevos servicios y ayudas de tipo extraordinario vinculadas a las campañas militares de la Reconquista y que influyeron muy negativamente en el crónico endeudamiento asturiano. Así, a los habituales y ordinarios pagos de pechos foreros -viejos censos señoriales debidos a la Corona pero ya bastante limitados tras las exenciones forales-pedido y moneda forera, habrá que añadir las cargas extraordinarias vinculadas directamente con las campañas militares en la frontera, como el empréstito de 1200 maravedíes que en 1258 satisface el concejo de Oviedo para habilitar naves y galeras ${ }^{6}$.

Parece claro, pues, que las tasas impositivas que engordaron las arcas regias procedentes del Principado procedían en su mayoría de una fiscalidad directa, ya fuese, en función de las circunstancias, de carácter ocasional o permanente. Poco sabemos, sin embargo, del sistema recaudatorio relativo a estas tributaciones que debían llegar a la Corte desde las lejanas tierras asturianas -martiniegas, yantares, pedidos, monedas foreras- aunque presuponemos un sistema de recaudación

\footnotetext{
4 Muy bien estudiadas por Juan Ignacio RUIZ de LA PeÑa Solar, "Las haciendas concejiles en el Norte de la Península Ibérica. El ejemplo ovetense", en Finanzas y fiscalidad municipal, V Congreso de Estudios Medievales, León, 1997, págs. 507-552.

5 Una revisión de las fuentes fiscales conservadas para la Asturias medieval en nuestro reciente trabajo María Álvarez FernÁndeZ, "Fuentes de archivo locales y tipología documental para el estudio de la fiscalidad y las redes urbanas en la Baja Edad Media: el ejemplo de Asturias", en David Carvajal de la Vega, Imanol Vítores Casado, Javier Añíbarro Rodríguez (eds.), Poder, fisco y mercado en las ciudades de la Peninsula Ibérica (siglos XIV-XVI), Valladolid, 2016, págs. 39-68.

6 Cfr. por J. I. Ruiz de la Peña Solar, “Las haciendas concejlles...”, págs. 512-526, especialmente.
} 
bastante simple por el que el Rey determinaba una cantidad fija en función de la ciudad y, después, cada concejo calculaba una redistribución per cápita entre los vecinos ${ }^{7}$. Es bien sabido, no obstante, que tras el final de la Reconquista, los monarcas cedieron de manera generalizada en Castilla gran parte de los réditos de la Corona a los concejos urbanos, comenzando a partir de ese momento la consolidación de las haciendas municipales y de las finanzas urbanas ${ }^{8}$.

A fines de la Edad Media, el poder financiero de los concejos será cada vez mayor, situación que supieron aprovechar muy bien los monarcas. A lo largo del siglo XIV y desde el punto de vista fiscal se aprecian interesantes novedades tanto en la manera de gestionar la recaudación de los impuestos como en la tipología del sistema impositivo, dando paso la tradicional fiscalidad directa al protagonismo absoluto, a partir de este momento, de la indirecta.

Frente a aquella de carácter extraordinario, para cuya recaudación las ciudades recurrieron mayoritariamente al sistema del repartimiento, en el caso de los réditos transferidos desde el arca regis a los diferentes concejos para gestionar su propia supervivencia financiera ordinaria, como la alcabala, las ciudades procedieron de diversa forma, confiando su gestión a determinadas familias que pujaban por el control recaudatorio en pública almoneda, al mejor postor. En buena lógica, los arrendatarios de los distintos tributos contaban con obtener pingües beneficios económicos de esta situación, como así fue ${ }^{9}$.

Más allá de la valiosa información que las fuentes locales conservadas pueden brindar al medievalista interesado en estas cuestiones, los fondos custodiados en la Contaduría Mayor de Cuentas del Archivo General de Simancas son, sin duda, el mejor escaparate para conocer y comprender la fiscalidad regia y concejil a fines de la Edad Media. En efecto, en un estudio reciente dedicado al análisis de las cuentas del Principado de Asturias para esta época, E. García Fernández avanzaba las enormes posibilidades de estudio que, para la hacienda y fiscalidad

\footnotetext{
7 En efecto, sabemos que en Oviedo, el reparto del pedido de Alfonso IX de 1225 se hizo en base la capacidad económica de los contribuyentes, debiendo pagar ducentos morabetinos pro petito secundum valorem facultatem suarum (Ciriaco Miguel VigiL, Colección histórico-diplomática del Ayuntamiento de Oviedo, Oviedo, 1991, doc. núm. V, pág. 23) y las propias Ordenanzas municipales de 1274 establecen para la capital asturiana una serie de medidas tendentes a garantizar la recaudación equitativa de las tasas ibíd., doc. núm. XXXVII, págs. 64-69).

8 Vid., con carácter general, Manuel Sánchez Martínez, Denis Menjot (eds.), Fiscalidad de Estado y fiscalidad municipal en los reinos hispánicos medievales, Madrid, Casa Velázquez, 2006.

9 Analizamos este caso y otros ejemplos significativos en María Álvarez Fernández, "Por ser hombre de más honra: comportamientos urbanos y plataformas del poder en una ciudad de transición (Oviedo, siglos XV y XVI)", en María Ángeles Faya Díaz (coord.), Las ciudades españolas en la Edad Moderna: oligarquías urbanas y gobierno municipal, Oviedo, 2014, págs.209-237.
} 
asturianas, ofrece dicho $\operatorname{archivo}^{10}$. En aquellas páginas, presentaba las primeras conclusiones de una cata documental que tenía como objetivo el estudio de la contabilidad financiera asturiana gestionada por D. Pedro Niño, contador mayor de los Reyes Católicos y mayordomo de Isabel la Católica ${ }^{11}$. Recogiendo aquél testigo -dirá el propio autor que los investigadores interesados por todas estas cuestiones tienen un largo camino por recorrer, también en el Principado de Asturias $^{12}$ - procedemos ahora a la edición de una interesante relación de rentas asturiana fechada en 1494 y que confirma parte de los datos ya estudiados por el autor añadiendo nuevas e interesantes informaciones cuantitativas y fiscales ${ }^{13}$.

De ese mismo fondo documental castellano -Archivo General de Simancas, Contaduría Mayor de Cuentas, primera época- procede la Copia del valor de las rentas de las alcabalas y diezmos de la mar y fueros y derechos del Principado y Cuatro Sacadas de Asturias de Oviedo e de los juros y situados que en ellas ovo el año de I U CCCCXCIIII años ${ }^{14}$. Este interesante testimonio recoge el volumen en maravedíes de la contribución concejil asturiana a la Hacienda Regia por distintos conceptos, fundamentalmente alcabalas, fueros y derechos. Más allá de las cantidades totales devengadas por el Principado, que pormenorizadamente se detallan por concejos, el interés de este documento reside en la división parroquial interna de las demarcaciones concejiles incorporadas, permitiendo jerarquizar la red poblacional asturiana con una precisión mayor de la hasta ahora conocida e identificar la identidad de los arrendatarios de las rentas ${ }^{15}$.

Comparando nuestros datos con los proporcionados recientemente por E. García para 1498 (Véase Apéndice, Cuadro 1) puede apreciarse, en primer lugar, que muchas de las cantidades liquidadas en maravedíes son idénticas: así, en orden descendente, Villaviciosa (264.186), Pravia (250.231), Oviedo (224.442), Parres, Cangas de Onís, Onís, Cabrales, Caso, Ponga y Amieva (214.878), Gijón (193.963), Siero (171.386), Grado (130.338), Valdés (128.565), Avilés (128.296), Ribadesella (111.950), Colunga (109.702), Carreño (94.344), Piloña (89.811), Teverga, Quirós, Proaza, Santo Adriano, Yernes y Tameza (54.365), Gozón (45.881), Nava (40.846), Las Regueras (30.512), Cabranes (29.299), Sariego (26.118), Miranda (25.828), Sobrescobio (20.826), Corvera (20.929), Caravia

\footnotetext{
${ }^{10}$ Ernesto García Fernández, "Las cuentas del Principado de Asturias: hacienda y poder a fines de la Edad Media", en Hacienda, mercado y poder al norte de la Corona de Castilla en el tránsito del Medievo a la Modernidad, Valladolid, 2015, págs. 259-290.

${ }^{11}$ Ibidem, pág. 260.

${ }^{12}$ Ibidem, pág. 283.

${ }^{13}$ Son muchas las aportaciones del profesor García Fernández al conocimiento de la fiscalidad castellana para los siglos finales de la Edad Media. Vid., entre otros, los estudios de referencia más recientes citados en la bibliografía.

${ }^{14}$ AGS, CMC ( $1^{\text {a }}$ época). Legajo $4^{\circ}$, sin foliar.

${ }^{15}$ Vid. el mapa concejil que adjuntamos al final del trabajo.
} 
(14.462), los cotos de Tresali, Buyeres y San Bartolomé de Nava (11.801), el coto de Bimenes (6.811), la Ribera de Yuso (6.400), el coto de Villayón (2.786), el coto de Paderni (2.000), el lugar de Tazo, en Caso (1.735) y los cotos de Covadonga (1.388) y de Lodeña, con 460 maravedíes. Prácticamente imperceptibles son las diferencias, subiendo ligeramente, en Llanes (de 292.285 a 292.286), Salas (de 67.107 a 67.110), Llanera (de 48.299 a 48.300), Telledo y Jomezana (de 9.346 a 9.348), Castrillón (de 9.655 a 9.655,5), Illas (de 8.255 a 8.256) y Tudela (de 5.043 a 5.048) y disminuyendo, también con muy poco margen, en Lena, Langreo, Laviana, Entrego, Tiraña, Pajares (de 187.109 a 187.106), Aller (de 95.526 a 95.525), Morcín (de 9.321 a 9.320), La Ribera de Suso (de 8.136 a 8.135) y Riosa (de 3.297 a 3.296). La mayor diferencia, y aún así es mínima, es la que encontramos en Olloniego, cuya contribución disminuye desde los 6.388 maravedíes de 1494 a los 6.329 maravedíes de $1498^{16}$. Como podrá apreciarse Apéndice final (Cuadros 1 y 2) hemos ordenado los concejos asturianos en orden descendente según las cantidades abonadas, desde la más cuantiosa-Llanes-a la menor -coto de Lodeña-, pudiendo observarse no sólo los valores en dinero sino también en especie (cargas de pescado, naranjas, gallinas) quedando registradas igualmente las identidades de los receptores de la renta, en ocasiones colectivos, distribuidos por parroquias, una atractiva información que permite elaborar una red fiscal mucho más precisa y pormenorizada, como apuntábamos.

Muchos menos relevante es la información relativa a fueros, derechos y diezmos de la mar. De los primeros, que representan una partida menor y no pagan todos los concejos, sólo podemos precisar el aumento producido entre los 51.000 maravedís de 1483 que calculaba E. García y los 136.718 para el bienio 1498-1499 así como la aportación de los concejos de Cangas, Corias, Bárcena, Castropol, Grandas, Salime, Ibias, Cerredo y Degaña, con un total de 26.000 maravedíes (13.000/año) y Tineo, con 18.000 (9.000 maravedíes/año).

Los diezmos de la mar exigidos a los puertos asturianos de manera directa fue un concepto incluido, en la mayoría de los casos, dentro del genérico de las alcabalas (Apéndice, Cuadro 1) y no figuran por separado, al menos en las rentas analizadas ${ }^{17}$ : los 228.342 maravedíes recaudados en Villaviciosa en 1494 son en concepto de alcabalas y diezmos de la mar; lo mismo que Avilés (115.250 maravedíes). Sólo excepcionalmente se especifican las distintas partidas en Valdés, donde a la contribución inicial de alcabalas de 101.120 maravedíes se añadirían

\footnotetext{
16 La información para el año 1498 procede de E. García Fernández, "Las cuentas del Principado de Asturias", pág. 289.

${ }^{17}$ Téngase en cuenta que, bajo el nombre genérico de salín de Avilés, se arrendaban el salín y alfolíes de Avilés, Villaviciosa, Luarca (Valdés), Pravia, Ribadesella y Llanes, y su renta, como estimaba Miguel Ángel LADERO QuesADA, era ya bastante considerable para 1495, ascendiendo a 1.140.000. Véase, del autor, La Hacienda Real de Castilla en el siglo XV, La Laguna, 1973, págs. 180 y ss.
} 
después 6.000 maravedíes de puja y 10.000 de los diezmos de la mar, montando un total de 117.120 maravedíes. Sumando las cantidades tributadas por diezmos, en los casos en los que así se individualizan de la partida total de alcabalas, estaríamos hablando aproximadamente para 1494 de 40.000 maravedíes, cifra que debe ponerse en relación con las aportadas por E. García para los años 1415 (30.000), $1427-1430(10.000)$ y 1432-1434 (12.500) ${ }^{18}$. Asimismo, A. Rubio Martínez, en su estudio sobre la fiscalidad gallega en tiempos de Juan II daba una cifra aproximada para la Asturias de aquellos años, elevando la cantidad pagada a 30.000 maravedíes ${ }^{19}$. Nos movemos, pues, en unos márgenes más o menos paralelos.

Otra cuestión igualmente interesante que trasciende de estas rentas es la colocación de situados en las alcabalas y que, de nuevo, podemos confrontar con los datos aportados en los recientes estudios de E. García. La misma distribución que el autor presentaba es la que registra nuestra fuente, con unas cifras que presentan muy pocas variables. Podrá comprobarse (Apéndice, Cuadro 3) la excepcionalidad, en el conjunto de la alta nobleza asturiana, de la condesa de Luna, $\mathrm{D}^{\mathrm{a}}$. Juana Enríquez, con un situado que asciende a 200.000 maravedíes, distribuidos en las alcabalas de Villaviciosa, Siero, Avilés, Grado, Pravia, Lena, Aller y Oviedo. Junto a ella, pero mucho menos representativos, Juan Rodríguez de Baeza, Alonso de Quintanilla y Gonzalo Bernaldo de Quirós ${ }^{20}$. Lo mismo sucede con las instituciones eclesiásticas, cuyo valor total asciende a 60.730 maravedíes de los cuáles algo más de la mitad (39.560) son acaparados por la Iglesia de San Salvador. Algo menos significativos serán los juros del resto de instituciones eclesiásticas: los monasterios urbanos -Santa Clara a cierta distancia del resto- y el Hospital del Escamplero, en pleno camino de peregrinación a Santiago. Las cuantías de los concejos urbanos y de Pedro de Vigil, platero, miembro de la oligarquía urbana, serán, finalmente, mucho menos significativas.

Otro aspecto que puede ser considerado a partir de este rico testimonio documental y no menos interesante es el de las redes clientelares y financieras tejidas entre los arrendatarios de las rentas en los distintos concejos asturianos. En efecto, si tenemos presente que no se conserva ningún vestigio documental de las villas asturianas para la Edad Media -han desaparecido todos los archivos municipales, excepto el avilesino- este tipo de documentación nos da, hasta la fecha, la única información posible acerca de los arrendatarios de los impuestos y sus ámbitos de

\footnotetext{
$\overline{18}$ Cfr. M. García Fernández, op. cit.

${ }^{19}$ Dos partidos fiscales diferentes, luego dos rentas distintas: Vascongadas y Marina de Castilla, por un lado, y Galicia y Cuatro Sacadas de Asturias (villas de Llanes, Ribadesella, Tineo y Cangas, diferenciadas del resto para marcar la impronta señorial), por otro. Para la comparativa con la época de Juan II, véase el excelente trabajo de Amparo Rubio Martínez, "La Hacienda real en Galicia en tiempos de Juan II (1406-1454)", En la España medieval, vol. 31 (2008), págs. 413-474.

${ }^{20}$ La relación exhaustiva de cada monto en particular, en Apéndice, Cuadros 3, 4 y 5.
} 
actuación, pudiendo concluir la presencia continua de determinadas familias en los circuitos financieros y fiscales asturianos ${ }^{21}$. Bien puede notarse esta cuestión en la relación final que incorporamos a este estudio a modo de índice onomástico donde ya destacan, a simple vista, algunos miembros de las oligarquías asturianas controlando y gestionando las rentas de varias parroquias pertenecientes a un mismo concejo e, incluso en ocasiones, a concejos diferentes: es el caso, por citar sólo los ejemplos más significativos, de Nicolás Alonso, que acapara en sus manos la recaudación de ocho parroquias en el concejo de Villaviciosa o Juan de Junco, que controla dos parroquias y dos cotos en esa misma demarcación concejil o los excepcionales casos de Gutierre de Solís, que teje bajo su control la red fiscal de cuatro importantes parroquias del concejo de Gozón y la de las alcabalas de la villa de Avilés y Gonzalo Rodríguez de Granda, que hará lo propio en los concejos de Lena, Langreo, Laviana, Entrego, Tiraña y Pajares, la parroquia de La Marina, en el concejo de Villaviciosa y las de Majón, Ventosa y el coto de Belmonte, en el concejo de Grado.

El estudio pormenorizado de este interesante testimonio documental, resultado de una fugaz incursión documental en los ricos fondos de la Contaduría Mayor de Cuentas del Archivo General de Simancas que, sin duda, habrá de completarse con el estudio completo del legajo del que forma parte, permite concluir este brevísimo estudio introductorio como lo comenzamos, es decir, subrayando el grave peso de los tributos aplicados sobre la población pechera en una tierra, la asturiana, muy deficitaria, cuyas disminuidas haciendas locales a duras penas pudieron capear la escasez y hacer frente a unas exigencias financieras llegadas de la Corte que poco o nada tenían que ver con el nivel de liquidez de la mayoritaria masa contribuyente ${ }^{22}$.

\footnotetext{
${ }^{21}$ Estudiamos el comportamiento de estas familias burguesas y su papel de verdaderos agentes fiscales controladores y dominantes de la fiscalidad urbana en el Oviedo de principios del siglo XVI en nuestro estudio María Álvarez Fernández, "Por ser hombre...".

${ }^{22}$ Conclusión que bien puede trasladarse a otras ciudades de la Corona de Castilla, como recientemente se ponía de manifiesto en un interesante seminario científico organizado bajo el amparo del proyecto de investigación Poder, sociedad y fiscalidad en el entorno geográfico de la Cornisa Cantábrica en el tránsito del Medievo a la Modernidad (HAR2011-27016-C02-01) y que daba la luz en forma de monografía: Ernesto García Fernández, Juan Antonio Bonachía Hernando (eds.), Hacienda, mercado y poder al Norte de la Corona de Castilla en el tránsito del Medievo a la Modernidad, Valladolid, Castilla Ediciones, 2015.
} 
APÉNDICE DOCUMENTAL

1494

Principado de Asturias. Rentas. Año de I U CCCCXCIIII. Copia del valor de las rentas de las alcabalas y diezmos de la mar y fueros y derechos del Principado y Cuatro Sacadas de Asturias de Oviedo e de los juros y situados que en ellas ovo el año de I U CCCCXCIIII años.

VALLADOLID, Archivo General de Simancas, Contaduría Mayor de Cuentas, Legajo 4.

Observaciones: El documento original, mucho más extenso, incorpora cartas de receptoría, relaciones de bienes y testimonios que, debido a su extensión, no son incorporados a la presente transcripción. En la misma se ha optado por mantener el sangrado original del documento inédito, indicando las cantidades tal y como figuran en él, sin alterar su posición.

Prinçipado de Asturias. Rentas. Año de I U CCCCXCIIII ${ }^{23}$.

Copia del valor de las rentas de las alcabalas y diezmos de la mar y fueros y derechos del Prinçipado y Quatro Sacadas de Asturias de

Oviedo e de los juros y situados que en ellas ovo el año de

I U CCCCXCIIII años.

-Las rentas de las alcabalas de paños y lienços e merçería y espeçeria y bohonería de la çibdad de Oviedo fueron arrendadores Rodrigo Sánchez de Aguilar e Juan de la Torre, mercaderes estantes allí; arrendose por quarenta y dos mill maravedíes.

XLII U

-La renta del vino de la dicha çibdad de Oviedo arrendáronla Juan de Oviedo e Alonso García de Granda por setenta e seys mill y quinientos.

\section{-Situado}

LXXVI U D

-Tiene de juro Alonso de Quintanilla de çierto pan y vino e dinero que está tasado en sesenta mill maravedíes.

LXU

-La renta del pescado de la dicha çibdad arrendola Diego de Dueñas criado de Diego de la Torre en siete mill e quinientos maravedíes.

VII U D

-La renta de las carnes vivas e muertas de la dicha çibdad arrendola Juan de Pravia por quarenta mill maravedíes.

XL U

$$
\text { -Situado }
$$

-Tiene de juro el monasterio de la Vega

IIII U

-Tiene de juro Sant Pelayo

II U CC

-Santa Clara en dos previllejos

VI U

-El monasterio de Sant Vicente

I U CC

\footnotetext{
$\overline{23}$ En margen izquierdo.
} 
-La renta del pan y plata y oro y çapatería y fierro y acero y peletería y heredades y paja y leña e carbón y canto y barro y sal y manteca e // fruta y ortaliza arrendose a Rodrigo Sánchez de Aguilar por quince mill y ochoçientos e çinquenta maravedíes.

-La renta de las bestias de la dicha çibdad arrendose a Diego de Santillana por mill maravedíes

- La çibdad de Oviedo dio porque le guardasen la condiçión que tenían en la alcabala con los carniçeros y mercado ${ }^{24} \mathrm{y}$ los que van a mercados y ferias francas doce mill maravedíes

\section{-Situados en la çibdad}

-El conde de Luna tenía situados en las rentas de Oviedo XXX U maravedíes. Mandaron a Juan Fernández de Barça $[\ldots]^{25}$ este año por librança del Regimiento en las rentas del pan y plata y las otras de suso y en los pescados y en las carnes porque se arrendaron este año por menudo.

\section{U}

-Las alcabalas del coto de Paderni arrendolas Gutierre de Parana en dos mill maravedíes.

-Las alcabalas del concejo de Tudela arrendaronse al concejo por quatro mill y trescientos y çinquenta y nueve maravedíes y doce gallinas.

-Las alcabalas del concejo de Olloniego, el concejo, çinco mill quatroçientos y setenta maravedíes y doce gallinas.

-Las alcabalas del coto de Cuevadonga, el abad de Cuevadonga, mill y doscientos maravedíes.

-Las alcabalas de los concejos de Lena y Langreo y Laviana y Entralgo y Tiranna y Pajares arrendaronse a Gonzalo Rodríguez de Granda por çiento y quarenta y nueve mill y sieteçientos y veynte maravedíes.

$$
\text { -Situado }
$$

-Tiene de juro el conde de Luna

XX U

-Tiene la Iglesia de Oviedo

-Tiene Santa Clara de Oviedo

III U//

-Las alcabalas de Telledo y Jomeçana arrendaronse a Gonzalo Suárez de la Cortina, creo que se dio en la copia del encabeçamiento en los VIII U LXXX maravedíes en que había estado. Después ovo puja de quatro, II U XX maravedíes que son diez mill y çient maravedíes y más quince quesos asaderos y dos açumbres de manteca.
XV U DCCCL

XII U

II U

IIII U CCCLIX

V U CCCCLXX

I U CC

CXLIX U DCCXX

-Las alcabalas del concejo de Sobrescobio arrendose al concejo por ${ }^{26}$.

\footnotetext{
${ }^{24}$ Sic pro mercadores.

${ }^{25}$ Tachado: [...]

${ }^{26}$ Sigue espacio en blanco.
} 
-Las alcabalas del concejo de Aller arrendaronse a Pedro Álvarez e a Diego de Murias e a Sancho García de Nembra por ochenta e dos mill y quatroçientos y treynta y quatro maravedíes y una vaca e doce quesos asaderos y dos açumbres de manteca.

LXXXII U

CCCCXXXIIII

-Situado

-Tiene de juro el conde de Luna

XX U

-Las alcabalas del concejo de Piloña arrendaronse a Diego de Cangas por setenta y siete mill y seysçientos y veynte y quatro maravedíes y dos puercos

LXX VII U DCXXIIII

-Las alcabalas del concejo de Caso arrendaronse a Diego de Caso por mill y quinientos maravedíes.

I U D

-Las alcabalas de los concejos de Parres y Cangas y Onís e Cabrales y Caso y Ponga y Amieva arrendaronse a Gonzalo Fernández de Granda por çiento y setenta y seys mill y doscientos y veynte maravedíes y dos cántaras de manteca.

-Las alcabalas de los cotos de Tresali y Buyeres y el coto de Sant Bartolomé de Nava arrendaronse a Gonzalo Monis de Nava por diez mill y doscientos y dos maravedíes.

-Las alcabalas del coto de Bimenes arrendaronse a Mosén de Oviedo por çinco mil y ochoçientos y ochenta y ocho maravedíes y doce perdices.

-Las alcabalas del concejo de Nava arrendaronse a Gonzalo Monis de Nava por treynta e çinco mill y trescientos maravedíes y quatro puercos //

-Las alcabalas del coto de Villayón arrendaronse a Diego de la Pallariega e Fernando Suárez por dos mill y quatroçientos y nueve maravedíes y diez y ocho quesos de piñón.

-Las alcabalas del coto de Lodeña arrendaronse a Francisco de Valdés por quatroçientos maravedíes.

-Las alcabalas de Cabranes arrendaronse a Diego de Cangas por veynte e çinco mill e trescientos y veynte e quatro maravedíes y ocho gallinas -Las alcabalas del concejo de Siero arrendaronse por feligresías en esta manera:

-La Pola, Juan Velasco y otros, en once mill y ocho maravedíes y VIII capones.

XI U VIII

-Tiene de juro el conde de Luna

I U DCC XVIII

-Santa Marina, Alvar Rodríguez dende por quatro

mill y seysçientos e setenta y dos maravedíes y

quatro gallinas

-Tiene de juro conde de Luna
IIII U DCLXXII

DCCLXX
CLXXVI U CCXX

X U CC II

V U DCCCLXXXVIII

XXXV U CCC

II U CCCCIX

CCCC

XXV U CCCXXIV 
-Las alcabalas de Argüelles, Ruy González de

Argüelles en tres mill y tresçientos y treynta y

quatro maravedíes e ocho gallinas

III U CCCXXXIIII

-Tiene de juro conde de Luna

DCXXX

-Las alcabalas de Oteru Fernando Rodríguez dende

II U CVI maravedíes y VI gallinas

II U CVI

-De juro conde de Luna

DCCLXXX

-Las alcabalas de Hevya, Ruy González Manjón

en V U CCCLXII maravedíes e quatro capones.

-De juro conde de Luna

V U CCCLXII

-Las alcabalas de Lugones, Juan de Mieres,

IX U CCCXV maravedíes y VI gallinas

DCCC

-De juro conde de Luna

IX U CCCXV

-Las alcabalas de Arenas, Pedro Fernández de Arenas

II U CCCCXIX maravedíes y quatro gallinas

II U CCCCXIX

-De juro conde de Luna

CCCXCVI

-Las alcabalas de Teñana ${ }^{27}$, Pedro Devia

VII U CCCCLXXIII maravedíes VI gallinas

-De juro conde de Luna

VII U CCCCLXXIII

-Las alcabalas de San Martín de Vega de Poja,

I U CCC LXXX

los vecinos de la colaçión, VIII U DCXVIII

maravedíes IX gallinas

-De juro conde de Luna

VIII U DCXVIII

-Las alcabalas de Santisteban de los Caballeros,

Fernando de la Quintana, I U DCCCCIIII

maravedíes VI gallinas

I U DCCCCIIII

-De juro el conde de Luna

DC

-Las alcabalas de Sant Juan de Muñó,

Juan González de Tiranna, III U CC maravedíes

XII gallinas

I U CCCLXXX

-De juro el conde de Luna

-Las alcabalas de Sant Juan de Celles,

Fernando Pérez del Otero, III U CXVI maravedíes

VIII gallinas

III U CXVI

DLXXII

-Las alcabalas de Sant Juan del Obispo Diego

de Mieres DCCXLII maravedíes IIII capones.

-De juro el conde de Luna

DCCXLII

CCLX

\footnotetext{
${ }^{27}$ Sic pro Tiñana
} 
-Las alcabalas de Boves, Esteban Rodríguez, IIII U CCCCXXVII maravedíes.

IIII U CCCCXXVII

-De juro el conde de Luna

I U DCCCCL//

-Las alcabalas de Valdesoto, Pedro Fernández

de Faes XXI U XXIX maravedíes XII capones

-De juro el conde de Luna

XXI U XXIX

III U DCX

-Las alcabalas de Mieres de Limanes, Juan del Fueyo,

II U CVI maravedíes IIII gallinas y dos capones

II U CVI

-De juro el conde de Luna

$\mathrm{CCCC}$

-Las alcabalas de La Collada, Juan García,

IIII U CLXXIII maravedíes XII gallinas

IIII U CLXXIII

-De juro el conde de Luna

DCCCCV

-Las alcabalas de La Peral y La Felguera,

Rodrigo Manjón, III U DCLXXXVI maravedíes

e medio y una açumbre de miel.

III U DCLXXXVI e medio

-De juro el conde de Luna

DCX

-Las alcabalas de San Martín de Anes,

Alonso González del Coto, XVII U DCI

maravedíes e medio y VIII gallinas

XVII U DCI e medio

-De juro el conde de Luna

III U DCCCCLXX

-Las alcabalas de Lieres, Fernando de Peñuli

V U DLXX maravedíes y VIII gallinas

V U DLXX

-De juro el conde de Luna

I U XXX

-Las alcabalas de Feleches, Alonso del Pedredo, IIII U DCCCCLII maravedíes y $\mathrm{X}$ gallinas.

-De juro el conde de Luna

IIII U DCCCCLII

DCCCCXX

-Las alcabalas de Vallino, Juan de la Puerta,

I U DCCCCLXXXIII maravedíes e medio

IIII gallinas

I U DCCCCLXXXIII e medio

-De juro el conde de Luna

$\mathrm{CCCC}$

-Las alcabalas de Sant Martín de La Carrera,

VIII U CXCVII maravedíes

VIII U CXCVII

-De juro el conde de Luna

I U CC//

-Las alcabalas de Collado, Fernando del Rebollar, I U DCCCCLV

maravedíes e medio y dos carneros

I U DCCCCLV e medio

-De juro el conde de Luna

CCCVII e medio

-Las alcabalas de Granda, Pedro Fernández

de Granda, IIII U DCLXXXVI maravedíes

XII gallinas

IIII U DCLXXXVI

-De juro el conde de Luna

I U D 
-Las alcabalas de Noçana, Gonzalo Rodríguez,

III U CCCCLXVI maravedíes e medio

VI gallinas

III U CCCCLXVI e medio

-De juro el conde de Luna

-Así que montan en todo el dicho arrendamiento del dicho conçejo de

Siero por feligresías çiento y quarenta e ocho mill y un maravedíes de más de la fruta.

CXLVIII U I

-Montan en el dicho juro que tiene el dicho conde de Luna según está repartido en el dicho conçejo XXX U maravedíes

XXX U

-Las alcabalas del concejo de Sariego túvolas el concejo en veynte y dos mill y quinientos y setenta y çinco maravedíes y XVIII gallinas.

-Las alcabalas y diezmos de la mar de la villa y concejo de Villaviçiosa arrendaronse por menudo y quando se dio la copia del encabeçamiento algunas feligresías no estaban arrendadas e se arrendaron después y valieron las unas y otras lo que adelante dirá en esta guisa:

-Las alcabalas y diezmos de la mar de la villa

de Villaviçiosa, Fuentes y Lugás, Diego de Molina,

LXVIII U CCCCXIIII maravedíes.

LXVIII U CCCCXIIII

-Del juro del conde de Luna

-De la merçed que tiene la villa en cada año

XV U maravedíes

XV U

-Del juro del monasterio de Valdediós, II U maravedíes//

II U

-Las alcabalas de la Marina, Gonzalo Rodríguez de Granda,

XX U CC maravedíes e çinco cántaros de azabache.

-Del juro del conde de Luna

XX U CC

$\mathrm{VU}$

-Las alcabalas de Grases y Camoca, Pedro Suárez

del Busto, IIII U XL maravedíes.

IIII U XL

-Del juro del conde de Luna

II U

-Las alcabalas de Cazanes, Pedro Suárez,

I U DC XXX maravedíes

I U DCXXX

-Las alcabalas de Selorio y Miravalles y

Carda y Sant Viçente y Tornón y Onón, Nicolás Alonso,

XXVI U LXVII y VI gallinas y capones

XXVI U LXVII

-Tiene de juro el conde de Luna en todas estas feligresías VII U

-Las alcabalas de Sant Martín del Mar,

Pedro de Muslera, III U maravedíes e un congrio.

III U

-Las alcabalas del Coro con los Pandos e

La Madalena, Nicolás Alonso, XV U CCVIII

maravedíes e medio y $\mathrm{X}$ gallinas

XV U CCVIII e medio

-Del juro del conde de Luna

IIII U 
-Las alcabalas de Estazones, Diego de Juan Sánchez, XXXII U maravedíes y tres docenas de pescado y mielgas y un congrio.

-Del juro del conde de Luna

-Las alcabalas de Bedriñana, Nicolás Alonso,

II U CCCXLIIII maravedíes y VI gallinas

II U CCCXLIIII

-Las alcabalas de Amandi, Ruy García de la

Poladura, VI U DCC

VI U DCC

- Las alcabalas de Castiello de Ambás, Rodrigo de la

Granda, I U DC maravedíes e çinco capones

I U DC

-Las alcabalas de Ternín y Valdebárcena, Juan de Junco,

IIII U maravedíes y VI gallinas

IIII U//

-El coto de Valdediós, Juan Sergo,

IX U DCC maravedíes y VI gallinas

IX U DCC

-Las alcabalas de Nievares y Rozadas,

Gonzalo de Suer Alfonso, VI U CCXXXVII maravedíes

y IIII gallinas

VI U CCXXXVII

-Del juro del conde de Luna

II U

-Las alcabalas del coto de Poreño y Çelada,

Juan de Junco, III U D maravedíes y XII gallinas

III U D

-Las alcabalas de Priesca, Juan de Lavares,

III U CCCXL maravedíes

III U CCCXL

-Las alcabalas del Valle de Peón, Rodrigo González

de la Riera, XVII U D maravedíes

XVII U D

-Del juro del conde de Luna

V U

Asy que monta en todo el dicho conçejo de Villaviçiosa

en la nómina que dicha es de más de la fruta, doscientas

e veynte y ocho mill y trescientos y quarenta y dos maravedíes.

CCXXVIII U CCCXLII

-El conçejo de Colunga arrendose por feligresías, diose en çierta

copia cuando el encabeçamiento porque algunas rentas no

estaban arrendadas y después se arrendaron e valieron las unas

y las otras es lo seguyente:

-La pola de Colunga, Alvar Rodríguez,

XXI U DCLX maravedíes

XXI U DCLX

-Lastres y Luces, Juan de Colunga, XXVI U DXCIIII

$\mathrm{y}$ quatro docenas de pescado y mielgas

XXVI U DXCIIII

-Guerres, Juan de Colunga, V U DCLXXII

maravedíes y una docena de mielgas y un congrio

V U DCLXXII

-El coto de Salas, Diego Sánchez, II U DCC

II U DCC

-Pernús, Diego de la Lora, V U DCC y dos gallinas

V U DCC

-Pivierda, Juan de Aldonça, I U CCXII maravedíes

I U CCXII 
-Libardón, Pedro de los Tojos, IIII U XL

IIII U XL

-La Isla, Diego Gutiérrez, III U XV maravedíes

II gallinas

III U XV//

-La Riera, Gonzalo de Pivierda, V U CCCLXIII

maravedíes

V U CCCLXIII

-Carrandi, Fernando de Carrandi, IIII U CXXVI

maravedíes e medio y quatro quesos IIII U CXXVI e medio

-Lué, Juan de Robredo, IIII U CXCVI maravedíes IIII U CXCVI

-Gobiendes, los vecinos de la colaçión,

VIII U DCLXXIX maravedíes

VIII U DCLXXIX

-Asy que montan en todo el dicho conçejo de Colunga en la manera que dicha es de más de la fruta, noventa y dos mill y nueveçientos y çinquenta y siete maravedíes e medio.

XCII U DCCCCLVII

e medio

-Las alcabalas del concejo de Caravia, el conçejo, doce mill e quinientos maravedíes.

XII U D

-Las alcabalas e diezmos de la mar de la villa y concejo de Ribadesella cuando se dio la copia de los encabeçamientos se dio en XCVII U DCXXIIII maravedíes e quatro docenas de pescado en que avía estado el año pasado; después se pujó en otros IIII U que son todos CI U DCXXIIII maravedíes y el pescado.

-Las alcabalas y diezmos de la mar de Llanes y su conçejo, Pedro hornero y Diego Ribero en CCLII U DCXXIIII y quatro arrobas de pescado y una de congrio por diez mil maravedíes de prometido

VII U D

- Tiene de juro Álvaro de la Torre

CCXLII U DCXXIIII

-Las alcabalas y diezmos de la mar del concejo de Gijón arrendaronse en menudo e según se dio la copia del encabeçamiento baxo una feligresía LXXXVI maravedíes y valieron las rentas lo seguyente:

CLXVII U CCCCL

-Las alcabalas y diezmos de la mar de la Pola con el coto de Natahoyo, Diego Suárez de Castiello,

LXVI U D maravedíes

LXVI U D

-Tiene de juro el conde de Luna

IX U

-Las alcabalas de La Pedreda y Lorio, Juan Morán,

XI U DCXXXVI maravedíes y doce gallinas

XI U DCXXXVI

-Tiene de juro el conde de Luna

I U CC//

-Las alcabalas de Hedia ${ }^{28}$ Menén Rodríguez

en III U CXVI maravedíes y VI gallinas.

III U CXVI

-Del juro del conde de Luna

CCL

CI U DCXXIIII 
-Las alcabalas de Deva, Diego del Campo,

VI U DCCLXXXI maravedíes y seis millares

de azabache

VI U DCCLXXXI

-Del juro del conde de Luna

DCC

-Las alcabalas de Pando, Alvar Rodríguez, DCC

DCC

-Del juro de la condesa de Luna

$\mathrm{XC}$

-Las alcabalas de Santa María de Ruedas ${ }^{29}$,

Diego González de la Madera, DCXVIII

DCXVIII

-Del juro de la condesa de Luna

LX

-Las alcabalas de la abadía de Yuso, Juan González

de Pinçales, VII U DXCII maravedíes y IIII gallinas. VII U DXCII

-Del juro de la condesa de Luna

DCCC

-Las alcabalas de la abadía de Suso, Alonso Fernández

de la Revellada, VII U CCXC y dos congrios

VII U XXC

-Del juro de la condesa de Luna

$\mathrm{DCCC}$

-Las alcabalas de Serino ${ }^{30}$, Pedro González

de Serino, IIII U CXCI maravedíes e medio

VI gallinas

IIII U CXC I e medio

-Tiene de juro la condesa de Luna

$\mathrm{D}$

-Las alcabalas de Sant Martín de Guerses ${ }^{31}$,

Gonzalo Rodríguez de Sant Martin,

II U DCXLI maravedíes y dos gallinas

II U DCXLI

-Del juro de la condesa de Luna

$\mathrm{CCC} / /$

-Las alcabalas de Caldones, Suer Fernández

de la Cuesta, III U LXXXV maravedíes e medio

y VI gallinas

III U LXXXV e medio.

-Las alcabalas de Somió, Gonzalo Fernández

de Quintueles, VIII U DCCCIII maravedíes

y VI gallinas

VIII U DCCCIII

-Del juro de la condesa de Luna

DCCCC

-Las alcabalas de Jove, Juan Menéndez, VI U D

y CCCC naranjas

VI U D

-Del juro de la condesa de Luna

DCC

-Las alcabalas de Vernueces, Álvaro de Vaones,

VI U DCXXIIII maravedíes y seys conteros

de azabache

VI U DCXXIIII

-Del juro de la condesa de Luna

DLXX

\footnotetext{
${ }^{29}$ Sic pro Ruedes.

${ }^{30}$ Sic pro Serín.

${ }^{31}$ Sic pro Huerces.
} 
-Las alcabalas de Veriña, Diego Fernández en I U CCCVIII y CC naranjas

I U CCCVIII

$\mathrm{XC}$

-Las alcabalas de Santo Millano ${ }^{32}$, Pelayo,

DC maravedíes y dos millares de azabache

-Del juro de la condesa de Luna

DC

CXX

-Las alcabalas de Val de Ranón ${ }^{33}$, Juan de

Quintana, III U DCXLI maravedíes y seys capones

III U DCXLI

-Del juro de la condesa de Luna

$\mathrm{CCCC}$

-Las alcabalas de Cagueñes ${ }^{34}$, Pedro Fernández

de la Piñera, V U CCCCLXX maravedíes

y VI gallinas

-Del juro de la condesa de Luna

V U CCCCLXX

$\mathrm{DCCC} / /$

- Las alcabalas de los Tacones Pedro

González de Serino III U CCCCXV maravedíes

y IIII gallinas

-Del juro de la condesa de Luna

III U CCCCXV

CXXX

-Las alcabalas del Fresno, Juan Sánchez en

III U maravedíes y IIII gallinas

III U

-Del juro de la condesa de Luna

CCCC

-Las alcabalas de Lavandera, Fernando González

de Linares, II U DCCCXXXIIII y XII gallinas

y dos capones

II U DCCCXXXIIII

-Del juro de la condesa de Luna

$\mathrm{D}$

-Las alcabalas de Sant Jorge y Santurio,

Alonso González de la Carriçera, I U CCXCVIII

-Del juro de la condesa de Luna

I U CCXCVIII

$\mathrm{CCC}$

-Las alcabalas de Fresno, Diego Álvarez de Fresno,

I U DCCXVIII

-Del juro de la condesa de Luna

I U DCCXVIII

CXX

-Las alcabalas de Çeares y Tremañes y

Aroles y Veranes, Alvar Pérez, V U

-Del juro de la condesa de Luna

-Asy que monta en todo el dicho conçejo de Gijón en la manera que dicha es syn la fruta y de más de ella çiento y sesenta y siete mill y quatroçientos y çinquenta maravedíes.

CLXVII U CCCCL

\footnotetext{
${ }^{32}$ Sic pro Santo Emiliano.

${ }^{33}$ Sic pro Valdornón.

${ }^{34}$ Sic pro Cabueñes.
} 
-Monta en todo el dicho juro de este concejo

según va repartido por las feligresías XX U

maravedíes los cuáles se mandaron a la Iglesia

de Sant Salvador de Oviedo.

$\mathrm{XX} \mathrm{U//}$

-El concejo de Carreño en la copia del encabeçamiento se dio en lo que avía estado el año de XCIII; después se arrendó por feligresías; valió LXXXIII U DCCXXXV maravedíes las alcabalas de más de la fruta en esta guisa:

LXXXIII U DCCXXXV

-Guymarán, Diego Cuervo

$\mathrm{V} \mathrm{U} \mathrm{CC}$

-Santolalla, Juan Álvarez,

IIII U D

-Prendes, Diego Alonso, dende IIII gallinas

I U CCCLXXXVI

-Ambás, Bartolomé de Ambás y IIII gallinas

II U CLI

-Turón y Carrión y Pervera, Alonso García

de Carrio II U DCCX maravedíes.

II U DCCX

LXXXIII U

-Tamón, Gonzalo Alonso de Tamón

VII U CLXXIX maravedíes y diez capones

-Perlora, Diego Alonso del Bustio,

VII U XXXIIII maravedíes y X gallinas

-Logreçana, Juan González, VI U CCCV

maravedíes y dos capones

DCCXXXV

-Piedeloro, los vecinos, D maravedíes

VII U CLXXIX

VII U XXXIIII

VI U CCCLV

-El puerto de Candás Juan de Grases,

XLVI U DCCXX maravedíes y dos mil sardinas

y quatro congrios

XLVI U DCCXX

-Tiene de juro Alvar Menéndez de Carreño

en este concejo

XX U

-Este concejo de Gozón, las alcabalas de él,

diose en el encabeçamiento en XXXIX U DCLVI

maravedíes. Non estaban arrendadas çiertas feligresías

y arrendaronse después e valió XXXIX U DCCCCLVI

maravedíes en esta guisa:

-El puerto de Luanco, Gonzalo de Luera

VIII U DCCC

-Nembro, Juan Álvarez de Guarín, III U CCCLXXXVI maravedíes y II capones

III U CCCLXXXVI

-Sant Martín de Boçines, el dicho Juan Álvarez, I U DCCCLXXIIII maravedíes

I U DCCCLXXIIII

-Valliniello, los vecinos, I U CLXXIIII

I U CLXXIIII

XXXIX U

-Sant Jorge de Mançaneda, Juan Fernández Dalvaro, I U DCXXIIII

DCCCCLVI maravedíes y dos capones

I U DCXXIIII//

-El carrizal, Juan Álvarez de Guarín,

I U DCCLXXXIIII maravedíes y II gallinas

I U DCCLXXXIIII

Cuadernos de Estudios Gallegos, LXIII, núm. 129 (2016), págs. 205-242. ISSN: 0210-847X. DOI: 10.3989/ceg.2016.129.06 
-Vioño, Juan Avilla, DCCL maravedíes

-El Valle de Heres, Gonzalo de Luera

-Santiago de Ambiedes y Sant Martín de Podes

e Laviana y Verdiçio e Sant Martín de Cardo,

Gutierre de Solís, XVI U CCCLX maravedíes

y diez capones.

-Que monta las dichas XXXIX U DCCCCLVI

maravedíes sin la fruta.

-Las alcabalas e diezmos de la mar de la Villa de Abillés, Gutierre de

Solís, CXV U CCL maravedíes y quatro docenas de pescado y en la copia del encabeçamiento iba este concejo en CI DC maravedíes. Las alcabalas y los diezmos de la mar IX U maravedíes, después pujaron las alcabalas IIII U DCL maravedíes e así son las dichas çiento y quince mil y doscientos e çinquenta maravedíes

-Tiene de juro la condesa de Luna

-Ysabel de Cuartona

-Las alcabalas de Castrillón, Fernando Cuervo de Abillés,

VIII U CCCXXIIII maravedíes y quatro capones

-Las alcabalas de Yllas, Pedro González de la Villa,

VII U CXVII maravedíes y seys capones

- Las alcabalas del concejo de Corvera, el concejo,

XVIII U XC y dos carneros y quatro capones

-Las alcabalas del concejo de Lanera, Gonzalo Fernández de Granda,

XXXVIII U CCXC maravedíes y XVIII gallinas

-Las alcabalas del concejo de Las Regueras, el concejo,

XXVI U CCCLXXII maravedíes y XVIII gallinas

-Tiene de juro el hospital de Escamprero, I U maravedíes

-Las alcabalas del concejo de Morcín, Gutierre Nuez,

VIII U LVII maravedíes y dos puercos

-Las alcabalas de la Ribera de Yuso, Diego de Cangas,

V U DXXXII maravedíes y quatro carneros

-Las alcabalas del concejo de Riosa, Gutierre Nuez,

II U DCCCL maravedíes y dos puercos

-Las alcabalas de la Ribera de Suso, Gutierre Nuez,

VII U XXXII maravedíes y VI gallinas

-Las alcabalas de los conçejos de Teverga y Quirós y Proaza y Santo

Adriano y Yernes y Tameza cuando se dio la copia del encabeçamiento non estaban arrendadas que ora son en XLVI U DCCCCLXXXVIII maravedíes en que avían estado y después se arrendaron a Gonzalo Fernández de Granda en LIII U maravedíes y una vaca.
CXV U CCL XXX U

VIII U CCCXXIIII

VII U CXVII

XVIII U XC

XXXVIII U CCXC

I U// XXVI U CCCLXXII

VIII U LVII

V U DXXXII

II U DCCCL

VII U XXXII 
-El concejo de Grado, las alcabalas sin otras feligresías del que era de yuso, al Vellaco por CIII U DCCLXIX maravedíes y doce capones y doce perdices.

-Tiene de juro la condesa de Luna

XXX U

-Las alcabalas de Majón y Ventosa y el coto de Valmonte, Gonzalo

Rodríguez de Granda y Luis Fernández el Viejo VII U DCCXCV maravedíes y dos lampreas y nueve quesos asaderos

-Las alcabalas de Trubia y Pintoria, Sancha Fernández de la Duerna,

II U DXXX maravedíes

-Las alcabalas del coto de Priañes, Álvaro y Pedro de Priañes,

I U CC maravedíes y IIII gallinas

-Las alcabalas de Grullos, Fernando Gómez en IU maravedíes este baxo

-Las alcabalas de Llamoso y Montovo y Sant Martin de Ondes, Martín

Fernández de Grado en I U CC maravedíes

-Esto susodicho es del concejo de Grado salvo el dicho coto de Valmonte, que es del concejo de Miranda y se encabeçó con Grado//

-Las alcabalas e diezmos de la mar del concejo de Pravia con el puerto de Cudillero, Sancho de Arango y Juan Fernández de Canedo y Alonso del Bustio y Juan Menéndez de Villazón en CCXVI U CCLXXVII maravedíes y LXIX libras de lino y hun salmón y dos gallinas y tres docenas de pescado e quatro congrios ceciales

-Tiene de juro la condesa de Luna

XXX U

-Las alcabalas del concejo de Salas, Sancho del Bustio en LVIII U maravedíes y doce capones y seys perdices y doce libras de lino.

-Las alcabalas del concejo de Miranda no estaban arrendadas cuando se dio la copia del encabeçamiento, dieronse en XXII U CCCXXIIII maravedíes y VI libras de lino e seys perdices en que avía estado; pujaron después II U maravedíes, que son XXIIII U CCCXXIIII maravedíes y la dicha fruta.

-Las alcabalas e diezmos de la mar del concejo de Valdés, cargaronse en la copia del encabeçamiento en lo del año pasado que eran CI U CXX maravedíes. Las alcabalas pujaron después VI U así que son con X U maravedíes de los diezmos de la mar, CXVII U CXX

-En todas estas rentas y arrendamientos entran todos derechos de diez maravedíes al millar y rendimientos e cartas de pago que todo va cargado por cuerpo de renta.

-Montan los fueros y derechos de todo el dicho Prinçipado CXXXVI

U DCCXXXVIII maravedíes según que cada consejo los debe cada uno su copia y según está en los libros de Sus Altezas.
CIII U DCCLXIX

VII U DCCXCV

II U DXXX

I U CC

I U

I U CC

CCXVI U

CCLXXVII

LVIII U

XXIIII U

CCCXXIIII

CXVII U CXX 
-Situados en ellos

-Tiene de juro la Iglesia de Oviedo en los fueros y derechos

del concejo de Grado, VII U DCC maravedíes

VII U DCC/

-Tienen situados el concejo de Siero y el monasterio de

Santa Clara de Oviedo en los fueros y derechos del

concejo de Siero cada uno III U CXXX maravedíes, que son VI U CCLX

VI U CCLX

-Tiene Sant Salvador de Oviedo en el río de Pravia,

III U DCCCCXL maravedíes

III U DCCCCXL

-Tiene el concejo de Salas en su mismo concejo.

III U

-Tiene la çibdad de Oviedo en la escribanía de la

dicha çibdad, IIII U maravedíes

IIII U

-Tienen los herederos de Diego Menéndez de Valdés

en los fueros y derechos del concejo de Gijón

IIII U

-Tienen los herederos de Martín Vázquez de Quirós

en los fueros y derechos del concejo de Grado

IIII U

-Tiene Gonzalo Bernaldo de merçed de por vida XXX U

maravedíes en los fueros y derechos de çiertos conçejos

XXX U

-Tiene Rodrigo de Carreño de merçed de por vida en los

fueros y derechos de los concejos de Carreño y Gijón

IIII U DC

-Tiene Pedro de Vigil en los fueros y derechos

del concejo de Colunga

II U DXX//

\section{ÍNDICE ONOMÁSTICO ${ }^{35}$}

Aldonza, Juan de: parroquia de Pivierda (Colunga)

Alonso, Diego: parroquia de Prendes $(\mathrm{Ca}-$ rreño)

Alonso, Nicolás: parroquias de Coro, Los Pandos y La Magdalena, Selorio, Miravalles, Carda, San Vicente de Tornón y Bedriñana (Villaviciosa)

Alonso de Tamón, Gonzalo: parroquia de Tamón (Carreño)

Alonso del Busto, Diego: parroquia de Perlora (Carreño)
Álvarez, Juan: parroquia de Santolalla (Carreño)

Álvarez, Pedro: concejo de Aller.

Álvarez de Guarín, Juan: parroquias de El Carrizal, Nembro y San Martín de Bocines (Gozón)

Álvarez del Fresno, Diego: parroquia de Fresno (Gijón)

Ambás, Bartolomé de: parroquia de Ambás (Carreño)

Arango, Sancho de: concejo de Pravia, con el puerto de Cudillero.

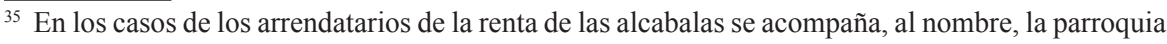
y el concejo donde ejercieron el cargo. Cfr. con Apéndice, cuadro 2.
} 
Avilla, Juan: parroquia de Vioño (Gozón)

Baones, Álvaro de: parroquia de Bernueces (Gijón)

Bernaldo, Gonzalo.

Bustio, Sancho del: concejo de Salas.

Campo, Diego del: parroquia de Deva (Gijón)

Cangas, Diego de: concejos de Piloña, Cabranes y Ribera de Yuso.

Carrandi, Fernando de: parroquia de Carrandi (Colunga)

Carreño, Rodrigo de.

Caso, Diego de: concejos de Caso.

Colunga, Juan de: parroquias de Lastres, Luces y Guerres (Colunga)

Cuartona, Isabel de.

Cuervo, Diego: parroquia de Guimarán (Carreño)

Cuervo de Avilés, Fernando: concejo de Castrillón.

De Juan Sánchez, Diego: parroquia de Tazones (Villaviciosa)

Dueñas, Diego de (criado): arrendador de la renta del pescado en Oviedo.

Fernández, Diego: parroquia de Veriña (Gijón)

Fernández, Luis (el Viejo): parroquias de Majón, Ventosa y coto de Belmonte (Grado)

Fernández Dálvaro, Juan: parroquia de San Jorge de Manzaneda (Gozón)

Fernández de Arenas, Pedro: parroquia de Arenas (Siero)

Fernández de Barça, Juan.

Fernández de Canedo, Juan: concejo de Pravia, con el puerto de Cudillero.

Fernández de Faes, Pedro: parroquia de Valdesoto (Siero)

Fernández de Grado, Martín: parroquias de Llamoso, Montovo y San Martín de Ondes (Grado)
Fernández de Granda, Gonzalo: concejos de Parres, Cangas de Onís, Cabrales, Caso, Ponga y Amieva.

Fernández de Granda, Pedro: parroquia de Granda (Siero)

Fernández de Quintueles, Gonzalo: parroquia de Somió (Gijón)

Fernández de la Cuesta, Suer (o): parroquia de Caldones (Gijón)

Fernández de la Duerna, Sancha: parroquias de Trubia y Pintoria (Grado)

Fernández de la Piñera, Pedro: parroquia de Cabueñes (Gijón)

Fernández de la Rebollada, Alonso: parroquia de la Abadía de Suso (Gijón)

Fueyo, Juan del: parroquia de Mieres de Limanes (Siero)

García, Juan: parroquia de La Collada (Siero)

García de Carrio, Alonso: parroquias de Turón, Carrión y Pervera (Carreño)

García de Granda, Alonso: arrendador de la renta del vino en Oviedo.

García de Nembra, Sancho: concejo de Aller.

García de la Poladura, Ruy: parroquia de Amandi (Villaviciosa)

Gómez, Fernando: parroquia de Grullos (Grado)

González, Juan: parroquias de San Juan de Muñó (Siero) y Logrezana (Carreño)

González de Argüelles, Ruy: parroquia de Argüelles (Siero)

González de Linares, Fernando: parroquia de Lavandera (Gijón)

González de Pinzales, Juan: parroquia de La Abadía de Yuso (Gijón)

González de Serín, Pedro: parroquias de Serín y San Andrés de los Tacones (Gijón)

González de Tiraña, Juan: parroquia de San Juan de Muñó (Siero)

González de la Carricera, Alonso: parroquias de San Jorge y Santurio (Gijón) 
González de la Madera, Diego: parroquia de Santa María de Ruedes (Gijón)

González de la Riera, Rodrigo: parroquia de Peón (Villaviciosa)

González de la Villa, Pedro: concejo de Illas.

González del Coto, Alonso: parroquia de San Martín de Anes (Siero)

González Manjón, Ruy: parroquia de Hevia (Siero)

Granda, Rodrigo de la: parroquia de Castiello de Ambás (Villaviciosa)

Grases, Juan de: el puerto de Candás $(\mathrm{Ca}-$ rreño)

Gutiérrez, Diego: parroquia de La Isla (Colunga)

Hevia, Pedro de: parroquia de Tiñana (Siero)

Junco, Juan de: parroquias de Ternín y Valdebárcena (Villaviciosa) y cotos de Poreño y Celada (Villaviciosa)

Lavares, Juan de: parroquia de Priesca (Villaviciosa)

Lora, Diego de la: parroquia de Pernús (Colunga)

Luera, Gonzalo de: puerto de Luanco (Gozón) y parroquia de Valle de Heres (Gozón)

Manjón, Rodrigo: parroquias de La Peral y La Felguera (Siero)

Menéndez, Juan: parroquia de Jove (Gijón)

Menéndez de Carreño, Alvar (o).

Menéndez de Valdés, Diego.

Menéndez de Villazón, Juan: concejo de Pravia, con Cudillero

Mieres, Diego de: parroquia de San Juan del Obispo (Siero)

Mieres, Juan de: parroquia de Lugones (Siero)

Molina, Diego de: la villa de Villaviciosa y las parroquias de Fuentes y Lugás (Villaviciosa)

Monis de Nava, Gonzalo: cotos de Tresali, Buyeres, San Bartolomé de Nava y el concejo de Nava
Morán, Juan: parroquias de La Pedreda y Lorio (de Gijón)

Murias, Diego de: concejo de Aller

Muslera, Pedro de: parroquia de San Martín del Mar (Villaviciosa)

Nuez, Gutierre: concejos de Morcín, Riosa y Ribera de Suso

Oviedo, Juan de: arrendador de la renta del vino en Oviedo

Oviedo, Mosén de: coto de Bimenes

Pallariega, Diego de la: coto de Villayón

Parana, Gutierre de: coto de Paderni

Pedredo, Alonso del: parroquia de Feleches (Siero)

Pedro (hornero): concejo de Llanes

Pelayo: parroquia de Santo Emiliano de la Vega (Gijón)

Piñuli, Fernando de: parroquia de Lieres (Siero)

Pérez, Alvar (o): parroquias de Ceares, Tremañes, Aroles, Veranes (Gijón)

Pérez del Otero, Fernando: parroquia de San Juan de Celles (Siero)

Pivierda, Gonzalo de: parroquia de La Riera (Colunga)

Pravia, Juan de: arrendador de la renta de las carnes vivas en Oviedo

Priañes, Álvaro de: coto de Priañes (Grado)

Priañes, Pedro de: coto de Priañes (Grado)

Puerta, Juan de la: parroquia de Vallino (Siero)

Quintana, Fernando de la: parroquia de San Esteban de los Caballeros (Siero)

Quintana, Juan de: parroquia de Valdornón (Gijón)

Quintanilla, Alonso de

Rebollar, Fernando del: parroquia de Collado (Siero)

Ribero, Diego: concejo de Llanes

Robredo, Juan de: parroquia de Lué (Colunga) 
Rodríguez, Álvar(o): parroquia de Santa Marina (Siero), la Pola de Colunga (Colunga) y parroquia de Pando (Gijón)

Rodríguez, Esteban: parroquia de Boves (Siero)

Rodríguez, Fernando: parroquia de Oteru (Siero)

Rodríguez, Gonzalo: parroquia de Nozana (Siero)

Rodríguez, Menén: parroquia de Hevia (Gijón)

Rodríguez de Granda, Gonzalo: concejos de Lena, Langreo, Laviana, Entrego, Tiraña y Pajares; parroquia de La Marina (Villaviciosa) y parroquias de Majón, Ventosa y coto de Belmonte (Grado)

Rodríguez de San Martín, Gonzalo: parroquia de San Martín de Huerces (Gijón)

Sánchez, Diego: coto de Salas (Colunga)

Sánchez, Juan: parroquia de Fresno (Gijón)

Sánchez de Aguilar, Rodrigo (mercader): arrendador de la renta de los paños, lienzos, mercería, especería y bohonería y de la renta del pan y plata, oro, zapatería, hierro, acero, peletería, heredades, paja, leña, carbón, canto, barro, sal, manteca, fruta y hortaliza de Oviedo.

Santillana, Diego de: arrendador de la renta de las bestias de Oviedo
Sergo, Juan: coto de Valdediós

Solís, Gutierre de: parroquias de Santiago de Ambiedes, San Martín de Podes y Laviana, Verdicio y San Martín de Cardo (Gozón) y de las alcabalas de Avilés

Suárez, Fernando: coto de Villayón

Suárez, Pedro: parroquia de Cazanes (Villaviciosa)

Suárez de Castiello, Diego: la Pola de Gijón, con el coto de Natahoyo

Suárez de la Cortina, Gonzalo: Telledo y Jomenzana.

Suárez del Busto, Pedro: parroquias de Grases y Camoca (Villaviciosa)

Suer Alfonso, Gonzalo de: parroquias de Nievares y Rozadas (Villaviciosa)

Tojos, Pedro de los: parroquia de Libardón (Colunga)

Torre, Álvaro de la.

Torre, Diego de la: arrendador de la renta del pescado en Oviedo.

Torre, Juan de la (mercader): arrendador de la renta de los paños, lienzos, mercería, especería y bohonería de Oviedo

Valdés, Fernando de: coto de Lodeña

Vázquez de Quirós, Martín.

Velasco, Juan: la Pola de Siero (Siero)

Vigil, Pedro de. 


\section{Cuadros Conclusivos}

Cuadro 1. Principado de Asturias. Renta de las alcabalas. Año de 1494.

\begin{tabular}{|c|c|c|}
\hline Concejo & Cantidad pagada en maravedís & Arrendador \\
\hline Llanes & $\begin{array}{c}242.624 \\
\text { (252.624 menos } 10.000 \text { de prometido) }\end{array}$ & Pedro, hornero, y Diego Ribero \\
\hline Villaviciosa (alcabalas y diezmos de la mar) & 228.342 & Recaudación parroquial (cuadro 2) \\
\hline Pravia & 216.277 & $\begin{array}{l}\text { Sancho de Arango, Juan Fernández } \\
\text { de Canedo, Alonso del Bustio, } \\
\text { Juan Menéndez de Villazón. }\end{array}$ \\
\hline Oviedo & 182.850 & Recaudación por mercancías \\
\hline $\begin{array}{l}\text { Parres, Cangas de Onís, Cabrales, } \\
\text { Caso, Ponga, Amieva }\end{array}$ & 176.220 & $\begin{array}{l}\text { Gonzalo Fernández de Granda } \\
\text { Diego de Caso }\end{array}$ \\
\hline Gijón & 167.450 & Recaudación parroquial (cuadro 2) \\
\hline $\begin{array}{l}\text { Lena, Langreo, Laviana, Entrego, } \\
\text { Tiraña, Pajares }\end{array}$ & 149.720 & Gonzalo Rodríguez de Granda \\
\hline $\begin{array}{c}\text { Siero } \\
\text { Grado, sin las feligresías de Yuso. }\end{array}$ & $\begin{array}{l}148.001 \\
103.769\end{array}$ & $\begin{array}{l}\text { Recaudación parroquial (cuadro 2) } \\
\text { Recaudación parroquial (cuadro 2) }\end{array}$ \\
\hline Valdés & $\begin{array}{l}117.120 \text { (101.120 iniciales + } 6.000 \text { de puja } \\
+10.000 \text { de los diezmos de la mar) }\end{array}$ & Sin especificar \\
\hline Avilés (alcabalas y diezmos de la mar) & 115.250 & Gutierre de Solís \\
\hline Ribadesella & $\begin{array}{c}101.624 \\
\text { (97.624 iniciales }+4.000 \text { de puja) }\end{array}$ & Sin especificar \\
\hline Colunga & $92.957,5$ & Recaudación parroquial (cuadro 2) \\
\hline Aller & 82.434 & $\begin{array}{l}\text { Pedro Álvarez, Diego de Murias, } \\
\text { Sancho García de Nembra. }\end{array}$ \\
\hline Carreño & 83.735 & Recaudación parroquial (cuadro 2) \\
\hline Piloña & 77.624 & Diego de Cangas \\
\hline Salas & 58.000 & Sancho del Bustio \\
\hline $\begin{array}{l}\text { Teverga, Quirós, Proaza, } \\
\text { Santo Adriano, Yernes y Tameza }\end{array}$ & 53.000 & Gonzalo Fernández de Granda \\
\hline Gozón & 39.956 & Recaudación parroquial (cuadro 2) \\
\hline Llanera & 38.290 & Gonzalo Fernández de Granda \\
\hline Nava & 35.300 & Gonzalo Monis de Nava \\
\hline Las Regueras & 26.372 & El concejo de vecinos \\
\hline Cabranes & 25.324 & Diego de Cangas \\
\hline Sariego & 22.575 & El concejo de vecinos \\
\hline Miranda & $\begin{array}{c}24.324 \\
\text { (22.324 iniciales más } 2.000 \text { de la puja) }\end{array}$ & Sin especificar \\
\hline
\end{tabular}




\begin{tabular}{|c|c|c|}
\hline Concejo & Cantidad pagada en maravedís & Arrendador \\
\hline Sobrescobio & Sin especificar & El concejo de vecinos \\
\hline Corvera & 18.090 & Sin especificar \\
\hline Caravia & 12.500 & Sin especificar \\
\hline $\begin{array}{c}\text { Cotos de Tresali, Buyeres } \\
\text { y S. Bartolomé de Nava }\end{array}$ & 10.202 & Gonzalo Monis de Nava \\
\hline Telledo y Jomenzana & 10.100 & Gonzalo Suárez de la Cortina \\
\hline Castrillón & $(8.080$ iniciales más 2.020 de puja) & Fernando Cuervo de Avilés \\
\hline Morćn & 8.324 & Gutierre Nuez \\
\hline Illas & 8.057 & Pedro González de la Villa \\
\hline Ribera de Suso & 7.117 & Gutierre Nuez \\
\hline Coto de Bimenes & 7.032 & Mosén de Oviedo \\
\hline Ribera de Yuso & 5.888 & Diego de Cangas \\
\hline Olloniego & 5.532 & El concejo de vecinos \\
\hline Tudela & 5.470 & El concejo de vecinos \\
\hline Riosa & 4.359 & Gutierre Nuez \\
\hline Coto de Villayón & 2.850 & Diego de la Pallariega \\
& 2.409 & Fernando Suárez \\
\hline Coto de Paderni & 2.000 & Gutierre de Parana \\
\hline Lugar de Tazo & Sin especificar \\
\hline Coto de Covadonga & 1.200 & Abad de Covadonga \\
\hline Coto de Lodeña & 400 & Fernando de Valdés \\
\hline Total alcabalas & $2.720 .668,5$ & \\
\hline Fueros y derechos & 136.718 & \\
\hline
\end{tabular}


Cuadro 2. Distribución parroquial de las alcabalas de los concejos de

Villaviciosa, Colunga, Siero, Gijón, Carreño, Gozón y Grado. Año 1494.

\begin{tabular}{|c|c|c|}
\hline $\begin{array}{c}\text { Tributación parroquial del concejo } \\
\text { de Villaviciosa }\end{array}$ & $\begin{array}{l}\text { Cantidad en } \\
\text { maravedíes }\end{array}$ & Receptor \\
\hline La villa, Fuentes y Lugás & 68.414 & Diego de Molina \\
\hline Tazones & 32.000 & Diego de Juan Sánchez \\
\hline Selorio, Miravalles, Carda, San Vicente de Tornón & 26.067 & Nicolás Alonso \\
\hline La Marina & 20.200 & Gonzalo Rodríguez de Granda \\
\hline Peón & 17.500 & Rodrigo González de la Riera \\
\hline Coro, Pandos, La Magdalena & $15.208,5$ & Nicolás Alonso \\
\hline El coto de Valdediós & 9.700 & Juan Sergo \\
\hline Amandi & 6.700 & Ruy García de la Poladura \\
\hline Nievares y Rozadas & 6.237 & Gonzalo de Suer Alfonso \\
\hline Grases y Camoca & 4.040 & Pedro Suárez del Busto \\
\hline Ternín y Valdebárcena & 4.000 & Juan de Junco \\
\hline Coto de Poreño y Celada & 3.500 & Juan de Junco \\
\hline Priesca & 3.340 & Juan de Lavares \\
\hline San Martín del Mar & 3.000 & Pedro de Muslera \\
\hline Bedriñana & 2.344 & Nicolás Alonso \\
\hline Cazanes & 1.630 & Pedro Suárez \\
\hline Castiello de Ambás & 1.600 & Rodrigo de la Granda \\
\hline TOTAL & $228.342^{1}$ & \\
\hline
\end{tabular}

\begin{tabular}{|c|c|c|}
\hline $\begin{array}{c}\text { Tributación parroquial del concejo } \\
\text { de Colunga }\end{array}$ & $\begin{array}{c}\text { Cantidad en } \\
\text { maravedíes }\end{array}$ & Receptor \\
\hline Lastres y Luces & 26.594 & Juan de Colunga \\
\hline La Pola de Colunga & 21.660 & Alvar Rodríguez \\
\hline Gobiendes & 8.679 & los vecinos de la collación \\
\hline Pernús & 5.700 & Diego de la Lora \\
\hline Güerres & 5.672 & Juan de Colunga \\
\hline La Riera & 5.363 & Gonzalo de Pivierda \\
\hline Lué & 4.196 & Juan de Robredo \\
\hline Carrandi & $4.126,5$ & Fernando de Carrandi \\
\hline Libardón & 4.040 & Pedro de los Tojos \\
\hline La Isla & 3.015 & Diego Gutiérrez \\
\hline Coto de Salas & 2.700 & Diego Sánchez \\
\hline Pivierda & 1.212 & Juan de Aldonza \\
\hline TOTAL & $92.957,5$ & \\
\hline & & \\
\hline & & \\
\hline
\end{tabular}

\footnotetext{
1 Suma real: 225.480,5 maravedíes.
} 


\begin{tabular}{|c|c|c|}
\hline $\begin{array}{c}\text { Tributación parroquial del concejo } \\
\text { de Siero }\end{array}$ & $\begin{array}{l}\text { Cantidad en } \\
\text { maravedíes }\end{array}$ & Receptor \\
\hline Valdesoto & 21.029 & Pedro Fernández de Faes \\
\hline San Martín de Anes & $17.601,5$ & Alonso González del Coto \\
\hline La Pola & 11.008 & Juan Velasco y otros \\
\hline Lugones & 9.315 & Juan de Mieres \\
\hline San Martín de la Vega de Poja & 8.618 & los vecinos de la parroquia \\
\hline San Martín de La Carrera & 8.197 & sin especificar \\
\hline Tiñana & 7.473 & Pedro de Hevia \\
\hline Lieres & 5.570 & Fernando de Piñuli \\
\hline Hevia & 5.362 & Ruy González Manjón \\
\hline Feleches & 4.952 & Alonso del Pedredo \\
\hline Granda & 4.686 & Pedro Fernández de Granda \\
\hline Santa Marina & 4.672 & Alvar Rodríguez \\
\hline Boves & 4.427 & Esteban Rodríguez \\
\hline La Collada & 4.173 & Juan García \\
\hline La Peral y La Felguera & $3.686,5$ & Rodrigo Manjón \\
\hline Nozana & $3.466,5$ & Gonzalo Rodríguez \\
\hline Argüelles & 3.334 & Ruy González de Argüelles \\
\hline San Juan de Muñó & 3.200 & Juan González de Tiraña \\
\hline San Juan de Celles & 3.116 & Fernando Pérez del Otero \\
\hline Arenas & 2.419 & Pedro Fernández de Arenas \\
\hline Mieres de Limanes & 2.116 & Juan del Fueyo \\
\hline Oteru & 2.106 & Fernando Rodríguez \\
\hline Vallino & $1.983,5$ & Juan de la Puerta \\
\hline Collado & $1.955,5$ & Fernando del Rebollar \\
\hline San Esteban de los Caballeros & 1.904 & Fernando de la Quintana \\
\hline San Juan del Obispo & 742 & Diego de Mieres \\
\hline TOTAL & $148.001^{2}$ & \\
\hline
\end{tabular}

\footnotetext{
2 Suma real: $147.112,5$ maravedíes
} 


\begin{tabular}{|c|c|c|}
\hline $\begin{array}{c}\text { Tributación parroquial del concejo } \\
\text { de Gijón }\end{array}$ & $\begin{array}{l}\text { Cantidad en } \\
\text { maravedíes }\end{array}$ & Receptor \\
\hline La Pola y el coto de Natahoyo & 66.500 & Diego Suárez de Castiello \\
\hline La Pedrera y Lorio & 11.636 & Juan Morán \\
\hline Somió & 8.803 & Gonzalo Fernández de Quintueles \\
\hline La Abadía de Yuso & 7.592 & Juan González de Pinzales \\
\hline La Abadía de Suso & 7.290 & Alonso Fernández de la Rebollada \\
\hline Deva & 6.781 & Diego del Campo \\
\hline Bernueces & 6.624 & Álvaro de Baones \\
\hline Jove & 6.500 & Juan Menéndez \\
\hline Cabueñes & 5.470 & Pedro Fernández de la Piñera \\
\hline Ceares, Tremañes y Veranes & 5.000 & Alvar Pérez \\
\hline Serín & $4.191,5$ & Pedro González de Serín \\
\hline Valdornón & 3.641 & Juan de Quintana \\
\hline S. Andrés de Los Tacones & 3.415 & Pedro González de Serín \\
\hline Hevia & 3.116 & Menén Rodríguez \\
\hline Caldones & $3.085,5$ & Suer Fernández de la Cuesta \\
\hline Fresno & 3.000 & Juan Sánchez \\
\hline Lavandera & 2.834 & Fernando González de Linares \\
\hline San Martín de Huerces & 2.641 & Gonzalo Rodríguez de San Martín \\
\hline Fresno & 1.718 & Diego Álvarez del Fresno \\
\hline Veriña & 1.308 & Diego Fernández \\
\hline San Jorge y Santurio & 1.298 & Alonso González de la Carricera \\
\hline Pando & 700 & Alvar Rodríguez \\
\hline Santa María de Ruedes & 618 & Diego González de la Madera \\
\hline Santo Emiliano de La Vega & 600 & Pelayo \\
\hline TOTAL & $167.450^{3}$ & \\
\hline
\end{tabular}

\footnotetext{
3 Suma real: 164.362 maravedíes.
} 


\begin{tabular}{|c|c|c|}
\hline $\begin{array}{c}\text { Tributación parroquial del concejo } \\
\text { de Carreño }\end{array}$ & $\begin{array}{c}\text { Cantidad en } \\
\text { maravedies }\end{array}$ & Receptor \\
\hline El puerto de Candás & 46.720 & Juan de Grases \\
\hline Tamón & 7.179 & Gonzalo Alonso de Tamón \\
\hline Perlora & 7.034 & Diego Álvarez del Busto \\
\hline Logrezana & 6.355 & Juan González \\
\hline Guimarán & 5.200 & Diego Cuervo \\
\hline Santolaya & 4.500 & Juan Álvarez \\
\hline Turón, Carrión, Pervera & 2.710 & Alonso García de Carrio \\
\hline Ambás & 2.151 & Bartolomé de Ambás \\
\hline Prendes & 1.386 & Diego Alonso \\
\hline Piedeloro & 500 & los vecinos de la parroquia \\
\hline TOTAL & 83.735 & \\
\hline & \multicolumn{2}{|c}{} \\
\hline
\end{tabular}

\begin{tabular}{|c|c|c|}
\hline $\begin{array}{c}\text { Tributación parroquial del concejo } \\
\text { de Gozón }\end{array}$ & $\begin{array}{c}\text { Cantidad en } \\
\text { maravedíes }\end{array}$ & Receptor \\
\hline $\begin{array}{c}\text { Santiago de Ambiedes, San Martín de Podes, } \\
\text { Laviana, Verdicio y San Martín de Cardo }\end{array}$ & 16.360 & Gutierre de Solís \\
\hline El puerto de Luanco & 8.800 & Gonzalo de Luera \\
\hline Valle de Heres & 4.204 & Gonzalo de Luera \\
\hline Nembro & 3.386 & Juan Álvarez de Guarín \\
\hline San Martín de Bocines & 1.874 & Juan Álvarez de Guarín \\
\hline El Carrizal & 1.784 & Juan Álvarez de Guarín \\
\hline San Jorge de Manzaneda & 1.624 & Juan Fernández Dalvaro \\
\hline Valiniello & 1.174 & los vecinos de la parroquia \\
\hline Vioño & 750 & Juan Avilla \\
\hline TOTAL & 39.956 & \\
\hline & &
\end{tabular}

\begin{tabular}{|c|c|c|}
\hline $\begin{array}{c}\text { Parroquias de yuso incorporadas al encabezamiento previo } \\
\text { del concejo de Grado (103.769 maravedíes) }\end{array}$ & $\begin{array}{c}\text { Cantidad en } \\
\text { maravedíes }\end{array}$ & Receptor \\
\hline $\begin{array}{c}\text { Majón y Ventosa } \\
\text { (el coto de Valmonte se encabeza con Miranda) }\end{array}$ & 7.795 & $\begin{array}{c}\text { Gonzalo Rodríguez de Granda } \\
\text { Luis Fernández, el Viejo }\end{array}$ \\
\hline Trubia y Pintoria & 2.800 & Sancha Fernández de la Duerna \\
\hline Coto de Priañes & 1.200 & Álvaro de PriañesPedro de Priañes \\
\hline Llamoso y Montovo & 1.200 & Martín Fernández de Grao \\
\hline Grullos & 1.000 & Fernando Gómez \\
\hline TOTAL (documento) & 13.995 & \\
\hline
\end{tabular}


Cuadro 3. Situados de la alta nobleza. 1494.

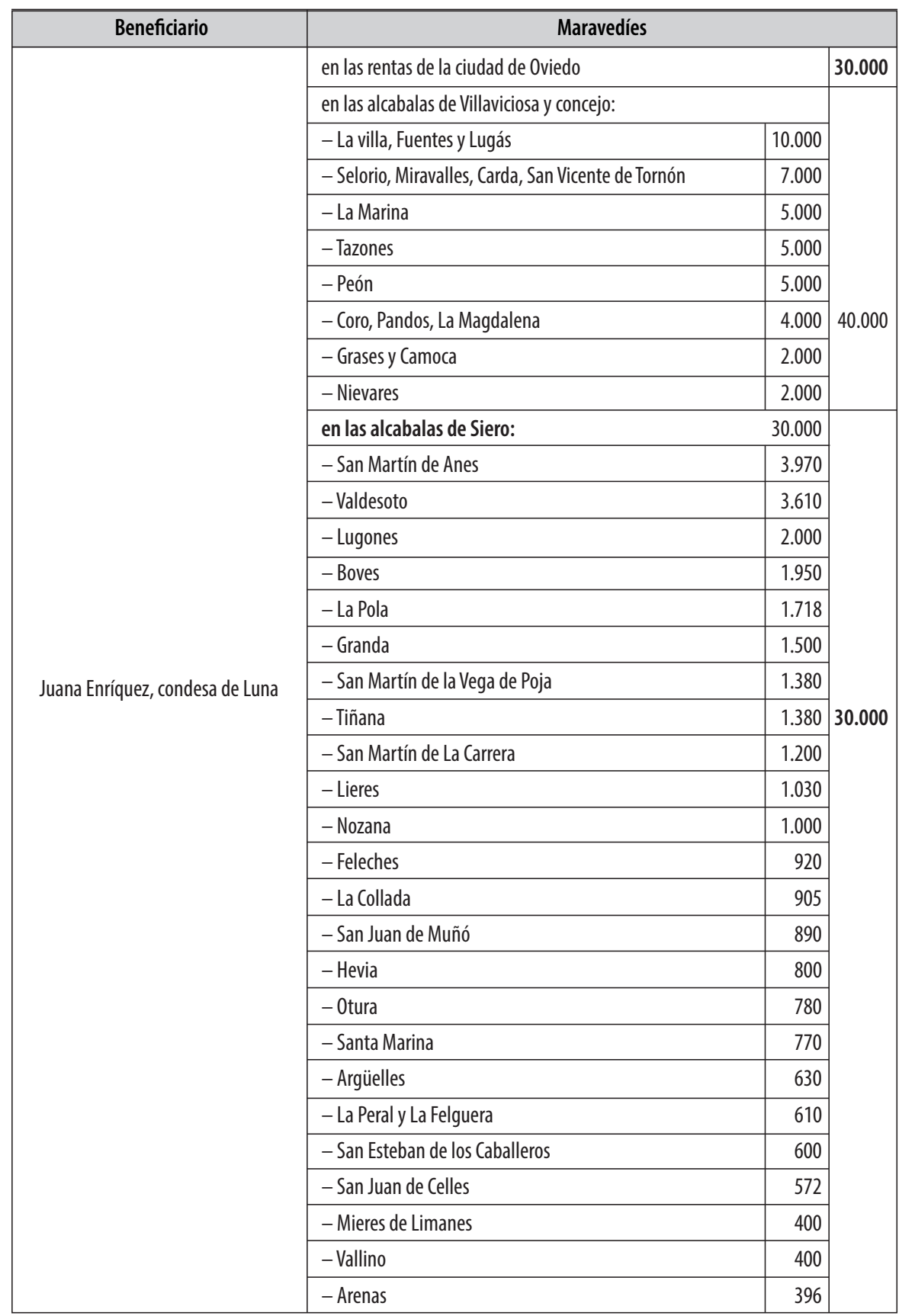




\begin{tabular}{|c|c|c|c|}
\hline Beneficiario & \multicolumn{3}{|l|}{ Maravedíes } \\
\hline \multirow{9}{*}{ Juana Enríquez, condesa de Luna } & - Collado & 307,5 & \\
\hline & -San Juan del Obispo & 260 & \\
\hline & \multicolumn{2}{|l|}{ en las alcabalas de Gijón (a la Iglesia de San Salvador de Oviedo) } & - \\
\hline & \multicolumn{2}{|l|}{ en las alcabalas de Avilés } & 30.000 \\
\hline & \multicolumn{2}{|l|}{ en las alcabalas de Grao } & 30.000 \\
\hline & \multicolumn{2}{|l|}{ en las alcabalas de Pravia } & 20.000 \\
\hline & \multicolumn{2}{|l|}{ en las alcabalas de Lena } & 20.000 \\
\hline & \multicolumn{2}{|l|}{ en las alcabalas de Aller } & 20.000 \\
\hline & \multicolumn{2}{|l|}{ en las alcabalas de Oviedo } & 10.000 \\
\hline $\begin{array}{l}\text { Isabel de Cuartona, } \\
\text { mujer de Alonso del Mármol }\end{array}$ & \multicolumn{2}{|l|}{ en la renta del vino de Avilés } & 10.000 \\
\hline \multirow{2}{*}{ Juan Rodríguez de Baeza } & \multicolumn{2}{|l|}{ en las alcabalas de 0viedo } & 20.000 \\
\hline & \multicolumn{2}{|l|}{ en las alcabalas de Pravia } & 10.000 \\
\hline Álvaro de la Torre & \multicolumn{2}{|l|}{ en las alcabalas de la villa de Llanes } & 7.500 \\
\hline \multirow{2}{*}{$\begin{array}{l}\text { Álvaro Menéndez de Carreño } \\
\text { (herederos) }\end{array}$} & \multicolumn{2}{|l|}{ en las alcabalas del concejo de Carreño y del puerto de Candás } & 20.000 \\
\hline & \multicolumn{2}{|l|}{ en la martiniega, derechos y salarios de la merindad de Avilés } & 1.200 \\
\hline $\begin{array}{l}\text { Rodrigo de Carreño, } \\
\text { alcaide de la fortaleza de Avilés }\end{array}$ & \multicolumn{2}{|l|}{$\begin{array}{l}\text { en los fueros, derechos, cáñama de la escribanía de Carreño } \\
\text { y de lo mismo, la mitad, en Gijón }\end{array}$} & 4.600 \\
\hline Diego de Miranda & \multicolumn{2}{|l|}{ en los fueros y derechos de Grao } & 4.000 \\
\hline Alonso de Quintanilla & \multicolumn{2}{|l|}{ en la renta del pan y del vino de 0viedo } & 60.000 \\
\hline Luis de Quintanilla (comendador) & \multicolumn{2}{|l|}{$\begin{array}{l}40 \text { cargas de trigo } \\
20 \text { cargas de cebada } \\
110 \text { cántaras de vino, en la renta del vino de Oviedo }\end{array}$} & 60.000 \\
\hline $\begin{array}{l}\text { Diego Menéndez de Valdés } \\
\text { (herederos) } \\
\text { Fernando Álvarez de Valdés } \\
\text { (hijo legítimo) }\end{array}$ & \multicolumn{2}{|l|}{ en los fueros y derechos de Gijón } & 4.000 \\
\hline $\begin{array}{l}\text { Martín Vázquez de Quirós } \\
\text { (herederos) }\end{array}$ & \multicolumn{2}{|l|}{ en los fueros y derechos del concejo de Grao } & 4.000 \\
\hline Gonzalo Bernaldo de Quirós & \multicolumn{2}{|l|}{ en ciertos concejos, de por vida } & 30.000 \\
\hline
\end{tabular}


Cuadro 4. Situados de la Iglesia de San Salvador de Oviedo y de los principales monasterios urbanos. 1494

\begin{tabular}{|c|c|c|c|}
\hline Beneficiario & \multicolumn{3}{|l|}{ Maravedíes } \\
\hline \multirow{28}{*}{$\begin{array}{l}\text { La Iglesia de San Salvador } \\
\text { de Oviedo }\end{array}$} & \multicolumn{2}{|l|}{ en las alcabalas de Gijón (la condesa de Luna): } & \multirow{23}{*}{20.000} \\
\hline & - La Pola de Gijón y el Natahoyo & 9.200 & \\
\hline & - La Pedrera y Lorio & 2.200 & \\
\hline & - Somió & 900 & \\
\hline & - La Abadía de Yuso & 800 & \\
\hline & - La Abadía de Suso & 800 & \\
\hline & - Cabueñes & 800 & \\
\hline & - Deva & 700 & \\
\hline & - Jove & 700 & \\
\hline & - Bernueces & 570 & \\
\hline & - Serín & 500 & \\
\hline & - Lavandera & 500 & \\
\hline & - Ceares, Veranes y Tremañes & 470 & \\
\hline & -Valdornón & 400 & \\
\hline & - Huerces & 300 & \\
\hline & - San Jorge y Santurio & 300 & \\
\hline & - Hevia & 250 & \\
\hline & - San Andrés de los Tacones & 130 & \\
\hline & - La Vega & 120 & \\
\hline & - Fresno & 120 & \\
\hline & - Pando & 90 & \\
\hline & - Veriña & 90 & \\
\hline & - Ruedes & 60 & \\
\hline & \multicolumn{2}{|l|}{ en las alcabalas de Pravia } & 1.920 \\
\hline & \multicolumn{2}{|l|}{ en los fueros y derechos de Grao } & 7.700 \\
\hline & \multicolumn{2}{|l|}{$\begin{array}{l}\text { en las alcabalas de Lena, Langreo, Laviana, Entrego, Tiraña } \\
\text { y Pajares }\end{array}$} & 3.000 \\
\hline & \multicolumn{2}{|l|}{ en el río de Pravia } & 3.940 \\
\hline & \multicolumn{2}{|l|}{ por un privilegio regio (sin especificar) } & 3.000 \\
\hline Monasterio de San Pelayo & \multicolumn{2}{|l|}{ en las alcabalas de Cuatro Sacadas del Principado de Asturias } & 2.200 \\
\hline Monasterio de San Vicente de Oviedo & \multicolumn{2}{|l|}{ en la renta de la carne de Oviedo } & 1.200 \\
\hline \multirow[t]{2}{*}{ Monasterio de La Vega de Oviedo } & \multicolumn{2}{|l|}{ en la renta de las carnes vivas y muertas de 0viedo } & 2.000 \\
\hline & \multicolumn{2}{|l|}{ en la renta de los paños, lienzos y mercería } & 2.000 \\
\hline Monasterio de Santa Clara & \multicolumn{2}{|l|}{ en los fueros y derechos de Siero } & 3.130 \\
\hline
\end{tabular}




\begin{tabular}{|c|c|c|}
\hline Beneficiario & Maravedíes & \\
\hline \multirow{4}{*}{ Monasterio de Santa Clara } & $\begin{array}{l}\text { en las alcabalas de Lena, Langreo, Laviana, Entrego, Tiraña } \\
\text { y Pajares }\end{array}$ & 3.000 \\
\hline & en la renta del pescado de Oviedo & 1.500 \\
\hline & en la renta de los lienzos y mercería de 0viedo & 1.500 \\
\hline & en la renta de la carne de 0viedo & 1.000 \\
\hline $\begin{array}{l}\text { Monasterio de San Francisco } \\
\text { de Oviedo }\end{array}$ & en los puertos de los diezmos de la mar de Asturias & 1.000 \\
\hline El monasterio de Valdediós & en la renta del vino de Villaviciosa & 2.000 \\
\hline El Hospital del Escamplero & en las alcabalas de Las Regueras & 1.000 \\
\hline
\end{tabular}

\begin{tabular}{|c|l|r|}
\hline Beneficiario & \multicolumn{1}{|c|}{ Colocación del situado y cantidad en maravedís } \\
\hline El concejo de Siero & en los fueros y derechos del concejo de Siero & $3.130^{4}$ \\
\hline El concejo de la ciudad de Oviedo & en la cáñama de la escribanía & 4.000 \\
\hline El concejo de Villaviciosa & en las alcabalas de la villa & $15.000^{5}$ \\
\hline El concejo de Salas & en las alcabalas de Salas & 3.000 \\
\hline
\end{tabular}

\footnotetext{
$\overline{4}$ En unas cuentas indica 3.130 y en otras 3.136 pero las sumas totales de todos los documentos remiten a 3.130 .

${ }_{5}$ Merced concedida en 1483 y por 15 años, luego 1498 es el último año que la disfruta.
} 


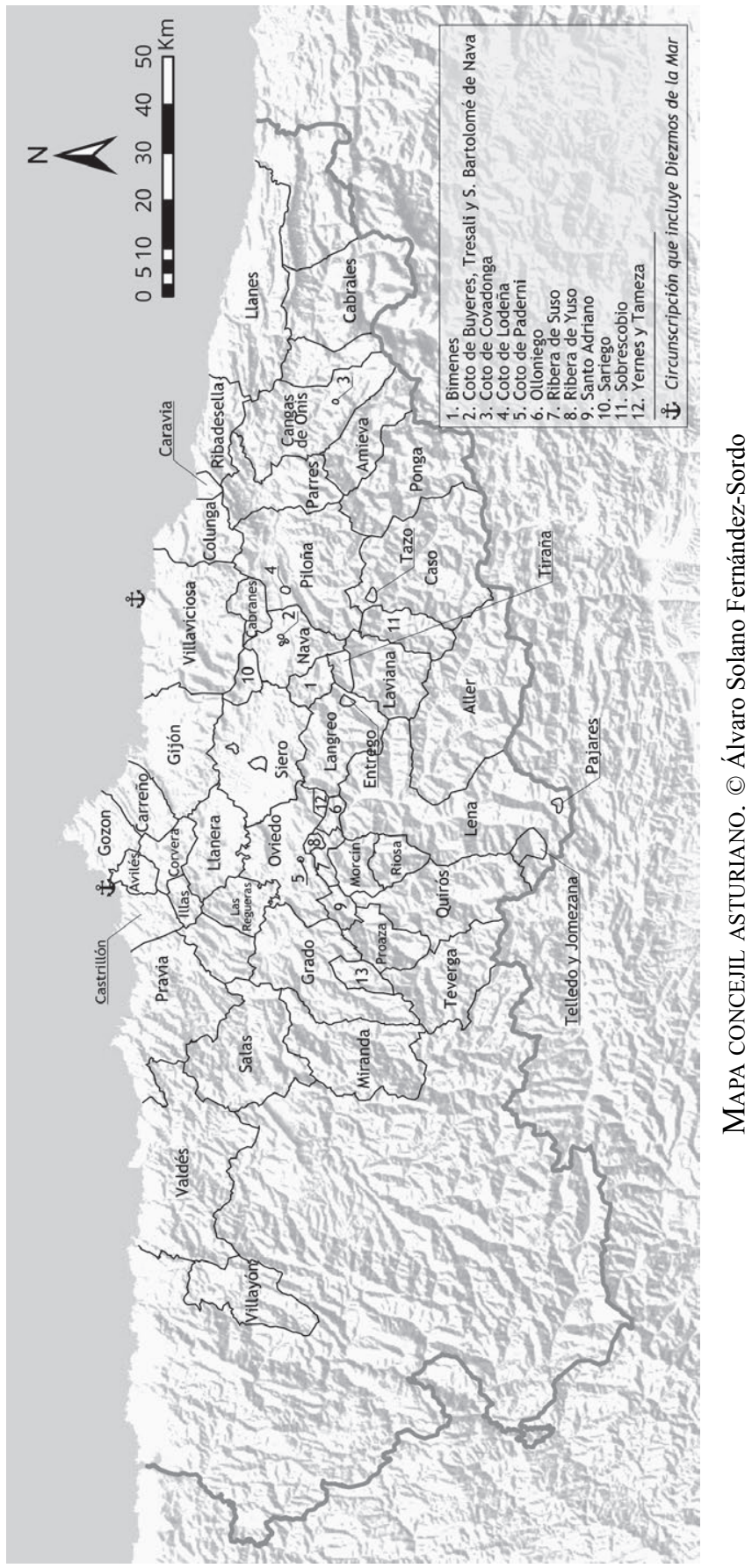




\section{BiBLIOGRAFÍA}

Álvarez Fernández, María, "Proyectos urbanos y políticas financieras para una ciudad moderna. Tradición e innovación en Oviedo (siglos XV-XVI)", en Hacienda, mercado y poder al norte de la Corona de Castilla en el tránsito del Medievo a la Modernidad, Valladolid, Castilla ediciones, 2015, págs. 437-468.

Carvajal de la Vega, David, Vítores Casado, Imanol, Añíbarro Rodríguez, Javier (eds.), Poder, fisco y mercado en las ciudades de la Península Ibérica (siglos XIV-XVI), Valladolid, 2016.

Faya Díaz, M. Ángeles (coord.), Las ciudades españolas en la Edad Moderna: oligarquías urbanas y gobierno municipal, Oviedo, 2014.

García Fernández, Ernesto, "Finanzas municipales y fiscalidad real en el País Vasco en el tránsito del Medievo a la Modernidad", en Menjot, Denis y Sánchez Martínez, Manuel (eds.), Fiscalidad de Estado y fiscalidad municipal en los reinos hispánicos medievales, Madrid, Casa Velázquez, 2006, págs. 171-196.

García Fernández, Ernesto, "La vida política y financiera de Vitoria a partir de las cuentas municipales de fines de la Edad Media", en Studia Historica. Historia medieval, 30 (2012), págs. 99-127

García Fernández, Ernesto, "Hacienda y fiscalidad en el País Vasco y La Rioja a finales de la Edad Media", en García Fernández, Ernesto y Goicolea Julián, Francisco Javier (eds.), Las haciendas medievales en el País Vasco y La Rioja. Textos para su estudio, Madrid, Instituto de Estudios Fiscales, 2012

García Fernández, Ernesto y Vítores Casado, Imanol (eds.), Tesoreros, “arrendadores” y financieros en los reinos hispánicos: la Corona de Castilla y el Reino de Navarra (siglos XIV-XVII), Madrid, Instituto de Estudios Fiscales, 2012

García Fernández, Ernesto y Galán Sánchez, Ángel (eds.), En busca de Zaqueo: los recaudadores de impuestos en las épocas medieval y moderna, Instituto de Estudios Fiscales, Madrid, 2012

García Fernández, Ernesto, “Alcabalas y gasto público en Guipúzcoa y Álava a fines de la Edad Media”, en Galán Sánchez, Ángel y Carretero Zamora, José Manuel (eds.), El alimento del Estado y la salud de la rex publica: origenes, estructura y desarrollo del gasto público en Europa, Instituto de Estudios Fiscales, Madrid, 2013, págs. 309-340

García Fernández, Ernesto, Bonachía Hernando, Juan Antonio (eds.), Hacienda, mercado y poder al Norte de la Corona de Castilla en el tránsito del Medievo a la Modernidad, Valladolid, 2015.

Ladero Quesada, Miguel Ángel, La Hacienda Real de Castilla en el siglo XV, La Laguna, Universidad de La Laguna, 1973.

Rubio Martínez, Amparo, "La Hacienda real en Galicia en tiempos de Juan II (1406-1454)", En la España medieval, vol. 31 (2008), págs. 413-474.

Sánchez Martínez, Manuel y Menjot, Denis (eds.), Fiscalidad de Estado y fiscalidad municipal en los reinos hispánicos medievales, Madrid, Casa Velázquez, 2006. 